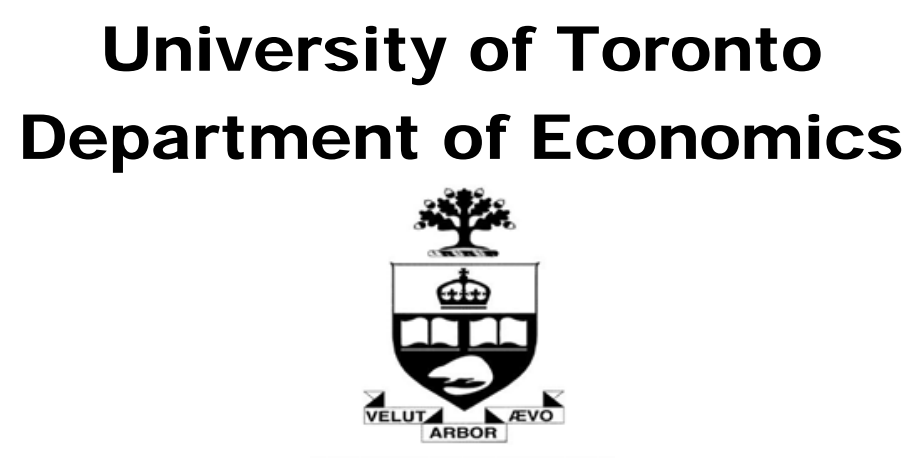

Working Paper 676

Price Discrimination along Multiple Dimensions: New Evidence from a Regional Airline

By Ambarish Chandra

September 17, 2020 


\title{
Price Discrimination along Multiple Dimensions: New Evidence from a Regional Airline*
}

\author{
Ambarish Chandra ${ }^{\dagger}$ \\ University of Toronto
}

September 15, 2020

\begin{abstract}
I examine the case of a firm that practices both second-degree and third-degree price discrimination. I present a model showing conditions under which the premium for higher quality can either rise or fall as the firm implements group pricing. I then use new data from a regional airline to estimate how the two kinds of price discrimination interact, and how each is affected by changes in competition. I establish three key results, all new to the literature. First, in different markets, the two kinds of price discrimination can either offset or reinforce each other, in a manner that fits the model's predictions. Second, inter-temporal differences in prices are purely driven by price discrimination, rather than by scarcity pricing. Third, competition increases the extent of both kinds of price discrimination.
\end{abstract}

\footnotetext{
*I thank Gaurab Aryal, Nate Baum-Snow, Rob Clark, Ricard Gil, Julie Mortimer, Eugene Orlov, Claudio Piga, Steve Puller, Henry Schneider and Alan Sorensen for helpful suggestions. I am especially grateful to Jim Dana for very useful discussions and insights. This research is funded by a SSHRC Insight Grant.

${ }^{\dagger}$ Department of Management, University of Toronto at Scarborough and Rotman School of Management, 105 St. George Street, Toronto, Ontario, M5S 3E6, Canada. Email: ambarishchandra@gmail.com
} 


\section{Introduction}

With the advent of large new datasets on consumer characteristics, and the proliferation of consumer tracking technologies, the ability of firms to price discriminate has grown tremendously. Firms, in many industries, now use sophisticated methods to target consumers, often using different kinds of price discrimination strategies simultaneously. It is increasingly common to see firms - in industries as varied as banking, publishing and online retailing - use both menu pricing and group pricing, at the same time, to maximize profits.

Price Discrimination is, of course, a central and long-studied topic in Microeconomics. But although the body of research in this area is vast, most prior work generally models firms as practicing either second-degree or third-degree price discrimination strategies. Theoretical studies tend to focus on just one or the other of these types in isolation, most likely due to the complexity inherent in models of multidimensional heterogeneity (Armstrong and Rochet, 1999). Empirical studies also tend to focus on just one type or the other, likely due to data constraints. However, there is no reason to believe that the results from partial analysis of each kind of discriminatory pricing will extend to environments where both kinds are implemented.

In this paper I present a stylized model, augmented with new data, to examine a setting where firms practice both kinds of price discrimination. In the model, a firm encounters different types of consumers arriving in each period who self-select into different quality levels. Thus, the change in prices over time for a given quality level represents third degree price discrimination, while the variation in prices for different quality levels at a given point in time represents second-degree price discrimination. ${ }^{1}$ The model shows that the premium for high quality service can either grow or shrink over time, as it depends on the composition of consumers that arrive in each period. Additionally, the model makes predictions about the share of the high-quality version that is sold in different markets.

I then turn to the airline industry, which is a setting where firms have long employed both types of discriminatory pricing to extract surplus, often in finely targeted ways. I obtain data from a regional airline that operates on routes within Canada, and between Canada and the United States. I examine price menus for various quality levels, as well as price discounts for advance purchases, to simultaneously examine both second- and third-degree price discrimination. I then examine how competition affects each of these practices, and establish key results that I compare to the model's predictions. I believe this is the first paper to use booking data directly from an airline to establish how firms price discriminate

\footnotetext{
${ }^{1}$ It is often assumed in the literature that advance purchase discounts are a form of second-degree price discrimination, but I argue that this practice represents group pricing more accurately than menu pricing. I discuss this issue in more detail in Section 2.1.
} 
according to advance purchases. Moreover, this is among the first empirical studies of how a firm simultaneously practices multiple types of price discrimination, especially in a setting where competition is important. ${ }^{2}$

Conceptually, the interaction of second-degree and third-degree price discrimination can have ambiguous effects on equilibrium prices or firms' profits. For example, if a firm has information about consumer characteristics through which to practice group pricing, this may enhance its ability to implement second-degree price discrimination, such as by offering more targeted options in its price menus. Thus, the ability to practice one kind of discriminatory pricing may make the other kind more lucrative. Conversely, though, it may be the case that once a firm has optimally implemented third-degree price discrimination, there may be less surplus available to extract from consumers through menu pricing, and therefore the two kinds of discriminatory pricing may conceivably offset each other.

The most important contribution of this paper is to show that second- and thirddegree price discrimination can reinforce each other in some markets, but offset each other in others. I first depict this using a model where the arrival rate of consumers with high and low willingness-to-pay for quality varies across markets. I then show that, in fact, there exist distinct airline routes in my data where the premium for higher-quality service either grows or shrinks as the airline practices temporal price discrimination. Moreover, the equilibrium shares of high- and low-quality tickets sold on each set of routes matches the theoretical predictions. To my knowledge, this contribution is entirely new to the literature.

The second contribution of this paper is to disentangle the role of price discrimination and inventory management in determining the evolution of fares over time. It is now well known that the optimal management of limited inventory can cause prices to vary over time even in the absence of price discrimination; for example, Sweeting (2012) shows that resellers of baseball tickets cut prices over time, due to declining opportunity costs of holding tickets as the game approaches. By contrast, firms in the airline industry not only need to dispose of a fixed inventory by a certain time, but can also price discriminate, as the enforcement of passenger identification eliminates resale. As a result, studies of the airline industry show that prices tend to rise over time as the date of the flight approaches. However, many such studies focus purely on monopoly routes due to the complexity that would be introduced by studying strategic interaction; for example, Lazarev (2013), Williams (2017), and Aryal et al. (2018).

I show that the temporal variation in fares for a given flight-date is not due to scarcity

\footnotetext{
${ }^{2}$ Prior authors have examined multiple kinds of price discrimination in monopoly, for example Leslie (2004). Some studies have examined competitive settings where firms may implement multiple kinds of discriminatory pricing, but focus on just one kind in their analysis (Lin and Wang, 2015), or examine how competition affects the type of price discrimination that firms use (Borzekowski et al., 2009).
} 
pricing, but is almost certainly because the firm implements price discrimination. I show that even routes or flight-days that have unusually high demand do not exhibit price gradients that are any steeper than those with normal or low demand. This is an important result because it is established using unambiguous measures of both fares and remaining inventory, as I have these variables directly from the airline, in contrast to previous work which has had to construct or infer measures of remaining inventory.

The third contribution of this paper is to establish new results regarding the effect of competition on second-degree and third-degree price discrimination. Past empirical work has generally been restricted to partial analysis of each kind of discriminatory pricing, and has come to differing conclusions with respect to the effects of competition. For example, Busse and Rysman (2005) and Lin and Wang (2015) in their studies of the effect of competition on second-degree price discrimination, asnd Borenstein and Rose (1994) and Gerardi and Shapiro (2009) when studying third-degree discrimination. Some theoretical models show that the effects of competition can be non-monotonic, e.g. Dai et al. (2014) and Chandra and Lederman (2017). However, a consideration that has not been noted by past authors is that many firms engage in both kinds of discriminatory pricing simultaneously, so that it may be important to account for each kind when examining how competition affects the other. My results indicate that the firm increases the extent of both kinds of price discrimination when it faces greater competition. Specifically, in markets with a lower Herfindahl Hirschmann Index, or a higher number of rivals, the advance purchase gradient is steeper and the premium for high quality service is greater.

While airlines have long been the setting for studying price discrimination, the available data have limited the extent of our understanding of this phenomenon. Specifically, the most common data source for analyzing prices in this industry has been the DB1B dataset provided by the U.S. Department of Transportation. One characteristic that is unavailable in this dataset is the date at which tickets were purchased. Since fares for a given flight tend to rise over time, it is highly likely that price differences over time for a given flight are due to the varying lengths of time in advance that tickets were purchased. Previous researchers have had to infer price dispersion or discrimination from the empirical distribution of ticket prices, with no knowledge of how much is due to advance purchase discounts versus other factors. It is only recently that some authors have been able to obtain, or construct, information on how fares vary over time for a given flight. ${ }^{3}$

My data source is a private airline based in Toronto, Ontario, which I will refer to as

\footnotetext{
${ }^{3}$ For example, Alderighi et al. (2015) scrape airfares from the website of Ryanair, Williams (2017) uses data from a search engine and Lazarev (2013) obtains airlines' published fares from a Global Distribution System.
} 
North Air. ${ }^{4}$ Though small compared to most well known airlines, North Air is an important player on the set of routes that it operates. North Air provided me with a $10 \%$ random sample of all its bookings, with information on the exact fares, date of travel, class of service and the number of passengers. Crucially, I also obtained the date of the booking, which allows me to calculate the length of the advance purchase period, and therefore examine price discrimination due to advance purchase. ${ }^{5}$ Additionally, the data allow me to calculate the remaining inventory of seats available at any point in time, which can potentially be an important constraint for any airline.

Knowing the remaining inventory of seats at any point in time is crucial for accurately understanding price discrimination. This is because firms that practice price discrimination according to advance purchases also generally have to contend with the management of a fixed inventory. For example, in theatre management, seats that remain unsold by the time of a given performance represent a lost revenue opportunity, and suggest that prices may have been too high. Conversely, a fully sold-out show eliminates the possibility of making lastminute sales to buyers with a high willingness-to-pay, implying that prices may have been too low. Thus, prices may rise or fall over time due solely to a firm's optimal management of its inventory, in a manner that is distinct from price discrimination over time. ${ }^{6}$ Indeed, it is common to observe temporal price changes for any kind of perishable good, even when price discrimination is absent; for example, discounts for food items just prior to their expiration, or steadily declining prices for baseball tickets as illustrated in Sweeting (2012).

Thus, the inventory management problem can contribute to price differences over time, that are distinct from price discrimination, and can make the analysis of dynamic price changing quite challenging, due to the complexity of the interaction between price discrimination and inventory management. Moreover, accurately constructing measures of remaining inventory has been another data challenge for past research. ${ }^{7}$ However, in this paper I address

\footnotetext{
${ }^{4}$ The airline prefers not to be named in print, though its identity should be easy to infer.

${ }^{5}$ Some recent studies have inferred discounts related to advance purchases by scraping the websites of airlines or of online travel agents. A key difference between these studies and mine is that using scraped data provides information on the distribution of offered prices, rather than on transacted prices. Moreover, when the lowest offered price changes from, say, one day to the next, it is not clear whether this is due to a smaller advance purchase window or because of a change in inventory due to the earlier fare being sold. My data distinguishes each kind.

${ }^{6}$ Past research has examined the interaction of the inventory management and price discrimination problems; for example, Dana and Williams (2016) provide a theoretical treatment and Alderighi et al. (2015) conduct an empirical analysis.

${ }^{7}$ Williams (2017) uses seat maps to construct the remaining inventory, at any point in time, for a given flight. Clark and Vincent (2012) do the same, but point out that this metric suffers from measurement error, and that it would be preferable to have daily load factor data directly from the airlines. Puller et al. (2009) obtain booking data, including fares and remaining inventory, from a Computer Reservation System, but this accounts, on average, for only about a third of bookings made on the flights they examine, leaving open the possibility that their constructed measures of load factors are calculated with error.
} 
this problem in a straightforward manner. I use the schedule of bookings made with the airline to reconstruct the history of purchases made, over time, for all flight-days. I combine this with information on the airline's capacity to work out the remaining number of seats at the time that each booking was made. These inventory measures are constructed with error, as I only observe $10 \%$ of the bookings with the airline rather than the full distribution. However, this error is mean zero and, by construction, uncorrelated with other key variables such as fares and the selection of passengers into different quality levels.

My empirical results strongly imply that the remaining inventory is not a factor in explaining the evolution of fares over time. Controlling for the number of remaining seats has no discernible effect on the price discrimination premiums that I estimate, and I show that the price discrimination gradients that I estimate are no different on routes, or routedays, with unusually high or low load-factors. Therefore, by isolating price discrimination as the cause of dynamic pricing, I show the presence of an advance purchase gradient even in the absence of scarcity pricing. This is an important finding because a number of papers in the literature have argued that advance purchase discounts may not necessarily reflect price discrimination, but may instead be the optimal profit-maximizing decision by a firm that faces uncertain demand, or for which demand is likely to exceed capacity (Gale and Holmes (1993), Dana (1998), Dana (1999), Möller and Watanabe (2010)). My results, however, show that even for a firm which is not inventory constrained, advance purchase discounts are a ubiquitous phenomenon, lending more support to the notion that advance purchase discounts are driven by price discrimination and not solely by optimal inventory management.

This paper is organized as follows. Section 2 discusses the terminology used in this paper, especially in the way it differs from past work, and also discusses the papers that are most closely related to this one. Section 3 presents the new data source used in this paper. Section 4 presents a stylized model of price discrimination along multiple dimensions. The empirical results are presented in Section 5. Section 6 concludes.

\section{Terminology and Literature}

\subsection{Terminology}

I now provide an important clarification regarding the terminology that I use in this paper. Throughout, I refer to quality-based price price discrimination as menu pricing, i.e. seconddegree price discrimination. More controversially, perhaps, I refer to inter-temporal price discrimination as group pricing, i.e. third-degree price discrimination. Prior research has often assumed that advance purchase discounts are a form of menu pricing, since they reason 
that consumers make a decision of when to purchase tickets and therefore self-select into more or less expensive fares (Dana, 1998). However, as in Chandra and Lederman (2017), I argue that this assumption should be reevaluated, especially in light of well known features of the airline industry. In reality, potential travelers are never presented with a menu of fares for advance purchase versus last-minute fares. Travelers who consider buying early are never sure what fares will be if they wait, while travelers who only learn of their travel plans at the last minute never have the option to travel back in time and purchase early.

Instead, most consumers are well aware that airfares tend to rise over time, and that it is in their interest to purchase as soon as their travel plans are known. Those who do so are likely travelers with fixed dates of travel, such as families or students, while those who learn at the last minute that they must travel are more likely to be business travelers, or those with a higher willingness-to-pay. Airlines infer, from how far in advance travelers wish to purchase tickets, which type they are, and charge them accordingly. Thus, I believe that advance purchase discounts should correctly be understood as a form of third-degree price discrimination. Indeed the model that I present in Section 4 makes this explicit, as consumers must purchase in the current period, or exit the market, and there is no possibility of strategic behaviour regarding the timing of purchase, nor are there capacity constraints which could cause the purchase of tickets in one period to affect the shadow cost of future sales.

Nevertheless, for those readers who disagree with this terminology, it is important to point out that none of this changes the analysis that follows. The point of the paper is that airlines practice at least two, very different, forms of price discrimination - one based on quality differences at a given point in time, and the other based on temporal differences for a given quality level.

\section{$2.2 \quad$ Literature}

The literature on price discrimination is vast, and both theoretical and empirical papers have focused on the two main classifications of second-degree and third-degree price discrimination. In this section I will briefly describe the most relevant papers for this study.

Few previous empirical papers have studied settings where firms practice both seconddegree and third-degree price discrimination. One exception is Leslie (2004), albeit in a monopoly setting. He examines Broadway theatre and distinguishes between menu pricingimplemented by offering consumers a range of quality levels of seats for a given performanceand group pricing, which is achieved by offering some consumers coupons, and also offering discounts for consumers willing to stand in line on the day of the event. Notably, Broadway 
theatres do not practice temporal price discrimination. Leslie estimates a discrete choice model of demand, and shows that firm profits are higher under discriminatory pricing than uniform pricing, while consumer surplus is essentially the same.

Aryal et al. (2018) also limit their analysis to monopoly markets. However, in other respects, the focus of their paper is similar to the setting studied here, as they also examine both inter- and intra-temporal price discrimination by airlines. They use a structural model to estimate a multi-dimensional distribution of consumers' preference heterogeneity, exploiting passengers' stated reasons for travel to distinguish between business and leisure travel. They use their results to estimate the extent to which allocative inefficiency can be attributed to demand uncertainty and asymmetric information.

Empirical studies of competition in second-degree price discrimination include Ivaldi and Martimort (1994) and McManus (2007). More recent empirical studies of second-degree price discrimination include Lin and Wang (2015) who show that the curvature of the hourly price schedule for parking garages decreases with competition. Specifically, short-term parking prices fall by more than long-term prices, making the price schedule more linear, and implying that competition constrains a firm's ability to practice second-degree price discrimination. This result is in contrast to Busse and Rysman (2005), for example, who find that competition increases the curvature of the price schedule in Yellow Pages advertising. Directories that face more competition see greater reductions in the prices of large ads than of small ads. ${ }^{8}$ Seim and Viard (2011) also show that, among wireless carriers, quantity discounts are larger in markets that see more entry.

It is worth noting that the empirical literature on second-degree price discrimination has focused mainly on quantity discounts (nonlinear pricing). While it is well known that quantity discounts are theoretically the same as offering varying quality levels, there are in fact, few empirical studies of the latter. This may be because quality can change and therefore is hard to measure or compare across different contexts. One noteworthy study of quality differences in second-degree price discrimination is Shepard (1991), who establishes that gasoline stations that sell both full-service and self-service gasoline are able to implement discriminatory pricing in a way that cannot be done by single-product stations. As I discuss below, quality levels are fixed in my setting too, as the airline offers the same amenities for high quality service across all its routes. This makes it feasible to study second-degree discrimination according to quality levels, as these do not change in response to demand or competition.

Within the empirical literature on third-degree price discrimination, there are well-

\footnotetext{
${ }^{8}$ Aryal and Gabrielli (2020) also study Yellow Page directories and show that competition is associated with substantial welfare gains, especially to low-type consumers.
} 
known disagreements regarding the effects of competition on price discrimination. ${ }^{9}$ Borenstein and Rose (1994) and Asplund et al. (2008) find that firms in more competitive markets offer a wider range of prices, while Gerardi and Shapiro (2009) find the opposite.

Within the theoretical literature, a number of studies have focused exclusively on either second-degree or third-degree price discrimination. Few papers examine both together, probably because of the complexity inherent in models of multi-dimensional screening (Armstrong and Rochet, 1999). The results of Rochet and Stole (2002) suggest that competition reduces quality distortions and reduces the dispersion in prices.

While price discrimination is probably a major reason for observing temporal price gradients, a number of prior studies argue that similar price dynamics can be achieved solely through the firm's optimal management of its inventory. Specifically, when a firm faces uncertain demand, or when demand is likely to exceed capacity, it can be optimal for prices to rise over time, even in the absence of a discriminatory pricing mechanism. This result is found by Gale and Holmes (1993), Dana (1998), Dana (1999) and Möller and Watanabe (2010). Interestingly, though, Sweeting (2012) shows that prices often decline over time, for a given game, in Major League Baseball, which is a setting where firms must optimally manage inventory but where temporal price discrimination is generally impossible. This apparent contradiction may be due to the fact that baseball games are less likely to be sold out.

\section{Data and Setting}

This section describes the data and establishes some simple, but important, empirical facts regarding both advance purchase price discrimination, and the menu of prices offered to consumers.

I obtained data from a small, private airline based in Toronto, which I refer to as North Air. The airline provided me with a $10 \%$ random sample of all its bookings, with information on the exact fares, date of travel, class of service. the number of passengers and, crucially, the date of the booking. ${ }^{10}$ I then calculate the length of the advance purchase period, which is the number of days between booking travel and the actual day of travel.

This data source represents a significant advance over prior studies that have tried to infer or construct measures of advance purchase discounts in the airline industry, or other

\footnotetext{
${ }^{9}$ Moreover, a number of studies tend to conflate price dispersion and price discrimination, such as Borenstein and Rose (1994) and Gerardi and Shapiro (2009), both of which use the observed variation in prices as a measure of price discrimination.

${ }^{10}$ I supervised the randomization myself, to ensure that the sample was truly representative along all of North Air's routes and itineraries.
} 
settings. Many prior papers have relied on the U.S. Department of Transportation's DB1B dataset to calculate measures of price dispersion. However, despite the wealth of information contained in the DB1B, it lacks a key piece of information that would enable researchers to study price discrimination comprehensively - the date of booking for each itinerary. As a result there is no way to tell how fares vary according to advance purchases, which is likely to be the most common and lucrative form of price discrimination by airlines. While other researchers have used creative way to try to obtain advance purchase pricing information, such as by monitoring and 'scraping' airline websites, accurate sources of information on this key element of firm behaviour are lacking.

North Air has a number of features that make it unlike most 'legacy' airlines but that are desirable from the point of view of my research design. First, it offers a single service cabin, with no distinction between leisure and business classes. ${ }^{11}$ Thus, in my analysis I can ignore the common type of second-degree price discrimination-between Coach and Business class cabins - practiced by most legacy carriers. Additionally, it does not follow the usual airline practice of offering different fare 'buckets', corresponding to different sets of restrictions, at varying prices. The legacy carriers implement this practice because prices and the quantity of sales are carried out by separate teams (Lazarev, 2013). This can make their pricing opaque, and makes it difficult to compare tickets in different buckets. Finally, the airline does not offer discounts or premiums for roundtrip or multi-city itineraries. A roundtrip itinerary is priced at exactly the sum of each individual journey, which makes it easy to compare the prices of tickets that are one-way or part of longer itineraries.

North Air offers just three fare groups on all of its routes, which I will refer to as Fixed, Adjustable and Refundable. These are distinct types of tickets with particular characteristics. On any given flight, all three options are available to purchase at any time. The main difference between the first two kinds of tickets is that Adjustable ticket holders can switch to earlier or later flights on the day of travel, while Fixed ticket holders must pay a fee, usually around $\$ 75$, to do so. Refundable ticket holders can not only switch flights on the day of travel, but can also have their entire purchase refunded at any time prior to the trip. ${ }^{12}$ As I will show below, North Air sells very few Refundable tickets, and it makes no difference whether I ignore these, or combine them with Adjustable tickets. I will refer to two main quality levels in my empirical analysis: Low and High fares. As all customers are shown a menu of these fares whenever they purchase a ticket, this clearly constitutes a form

\footnotetext{
${ }^{11}$ In this regard, the airline is similar to most low-cost carriers. However North Air is not exactly a low cost carrier. It offers certain premium features - to all passengers - such as free snacks in lounges and on board, and leather seats.

${ }^{12}$ There are a few other differences, such as with bag fees.
} 
of second-degree price discrimination. ${ }^{13}$

The dataset obtained from North Air contains information on over 900,000 itineraries, during 2008-2014. Each itinerary contains the following information: the date of the booking, the date of travel, the number of passengers on the itinerary, the start and end points of the journey, the connections on the way (if any), the fare group, the currency in which the ticket was purchased, and the fare paid. Crucially, I use the difference between the booking and travel dates to construct daysout, the number of days in advance of the journey that the reservation was made.

I restricted the initial 10\% random sample in the following ways. First, North Air offers service to and from 19 airports in Canada and the United States, during my sample period. The data contain information on journeys between all of these, as well as some journeys that began or terminated at around 10 other airports. The latter are not standard tickets for travel on North Air, and probably represent situations where travel agents combined tickets for travel on North Air with some other airline. I dropped these itineraries, which accounted for just 122 observations.

Next, I dropped observations that involved complicated multi-city itineraries with three or more separate journeys, which represented about $0.3 \%$ of the data. I then dropped itineraries where the fare group was listed as "Other", i.e. not one of the three standard fare groups. These were about $0.15 \%$ of the data. Finally, I also dropped observations where the recorded fare for the journey was less than $\$ 20$-which represented approximately $0.5 \%$ of observations - and are likely to have been either employee discount tickets or frequent-flyer reward tickets. I also dropped seven observations where the recorded fare was greater than $\$ 1300$. The final dataset consists of 865,492 observations, for travel between 19 airports, during the years 2008-2014.

As the data contain a $10 \%$ random sample of all flown itineraries, I can use this information to work out measures of the remaining inventory available to the airline when each seat is sold. This is important in order to distinguish capacity-based and discriminatory reasons for changing fares over time. I use two measures designed to capture the airline's remaining capacity. The first is the booking order which is the order in which each seat is sold, for travel on a given day for a given route. The idea is simply that tickets, for a given travel date, bought earlier are less likely to encounter a capacity constraint on the part of the airline. Although, as I will show below, this measure is correlated with the daysout variable, variation in booking order controlling for daysout indicates flights that are more or less full,

\footnotetext{
${ }^{13}$ North Air's various fare types are generally available at all times. This is unlike other airlines, Southwest Airlines in particular, where the cheapest fares often sell out in advance. North Air does occasionally experience Low fares being sold out, but that is the exception, not the norm. Figure 1 shows that Low Fares are sold at all times including right up until the day of travel.
} 
Table 1: Summary Statistics: Airline Data

\begin{tabular}{lccccc}
\hline & Mean & SD & Min. & Median & Max. \\
\hline One-way Base Fare (CAD/person) & 148 & 99.6 & 20 & 123 & 1296 \\
Passengers & 1.21 & 0.5 & 1 & 1 & 23 \\
Advance Purchase (Days) & 29.2 & 30.7 & 0 & 19 & 473 \\
Booking Order & 11.90 & 12.1 & 1 & 7 & 86 \\
Fixed Fare & 0.85 & 0.4 & 0 & 1 & 1 \\
Adjustable Fare & 0.13 & 0.3 & 0 & 0 & 1 \\
Refundable Fare & 0.01 & 0.1 & 0 & 0 & 1 \\
Return Journey & 0.81 & 0.4 & 0 & 1 & 1 \\
One-way Journey & 0.19 & 0.4 & 0 & 0 & 1 \\
Multi-City Journey & 0.00 & 0.1 & 0 & 0 & 1 \\
Nonstop & 0.86 & 0.3 & 0 & 1 & 1 \\
\hline
\end{tabular}

Note: An observation is an itinerary. $\mathrm{N}=865,492$

holding constant the days in advance that the reservation was made.

The second measure of the airline's remaining capacity is created by first constructing North Air's available seat inventory, for each route and travel day. I do this using data on flights and seats from OAG. I then divide this inventory by 10 (to account for the fact that I only observe $10 \%$ of the data) and subtract from it the number of seats that were already purchased on the route-date prior to the given itinerary being purchased.

Both of these capacity variables are measured with error, given that they are formed from the $10 \%$ random sample rather than from the full distribution. Importantly, however, the error is mean zero, and there is no reason to believe that it is correlated with the variables of interest, such as fares and the quality choices made by consumers, due to the randomization procedure that was used to generate the sample.

Table 1 presents summary statistics for the data. Each observation is an itinerary for travel on a certain date for a given route. The average reservation is made 29 days in advance of travel, has 1.2 passengers and costs around $\$ 148$ Canadian dollars. ${ }^{14} 85 \%$ of tickets are in the Fixed fare group, with $13 \%$ in the Adjustable group. Over $80 \%$ of tickets are part of return journeys, with the rest being one-way trips. The booking order for the average itinerary is 11.9 .

Figure 1 shows the detailed distribution of daysout, separately for the two main fare classes. I divide daysout into bins corresponding to some standard windows of advance purchase periods. Almost $20 \%$ of tickets are sold between one and two months in advance of travel, in the Fixed category. Around 5\% of tickets are sold either on the day of travel or one day prior. Fixed tickets tend to be purchased further in advance, while Adjustable

\footnotetext{
${ }^{14}$ One Canadian Dollar has ranged from the equivalent of 0.66-1.09 US Dollars during my sample period.
} 
Figure 1: Distribution of DaysOut

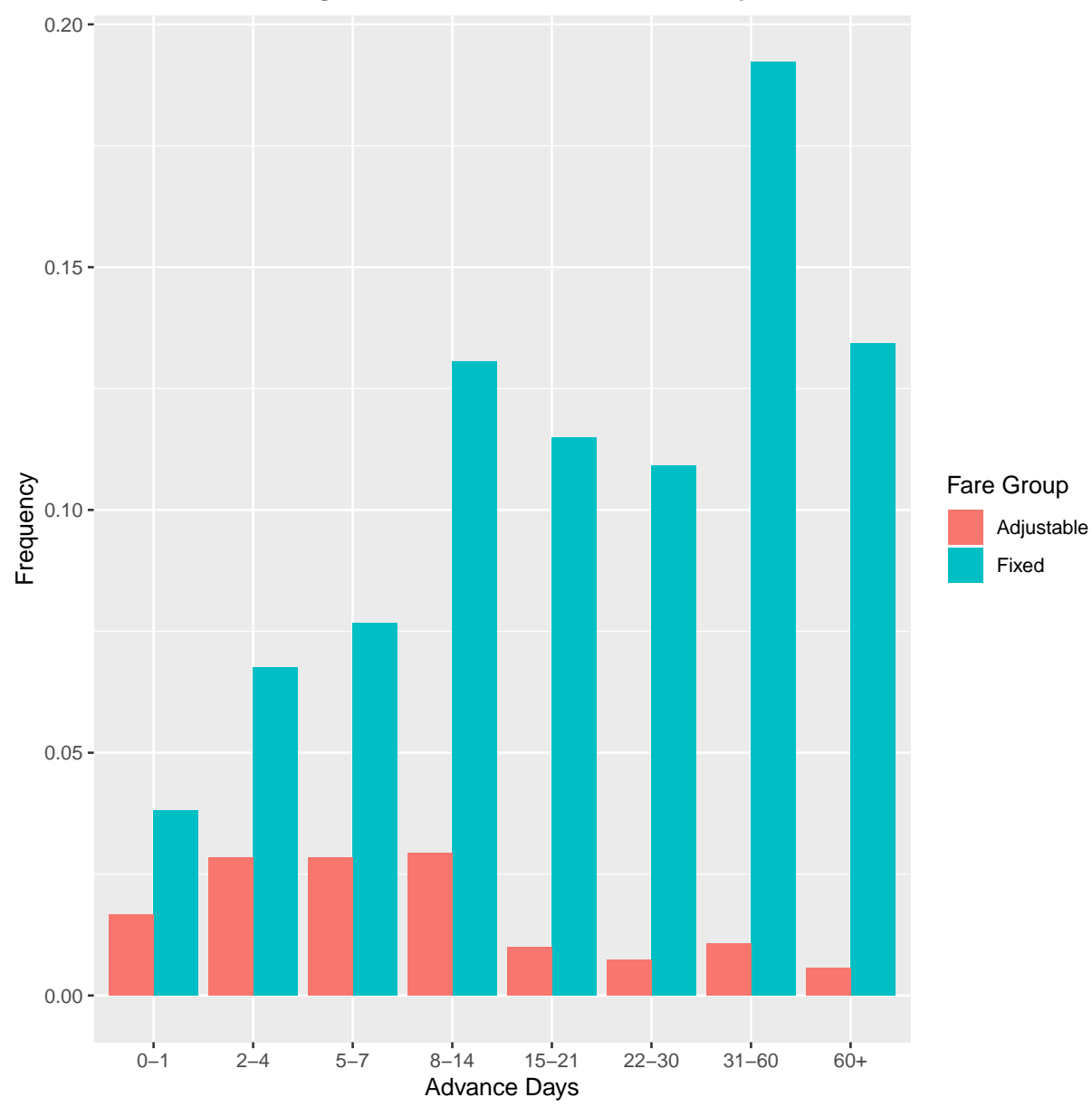

Notes: The figure plots the distribution of advance purchase days, separately for the Fixed and Adjustable Fare classes, across all routes and years in the data.

tickets tend to be purchased closer to the date of travel.

In order to calculate measures of competition, as well as accurate measures of remaining inventory, I used a second source of data from OAG, which is a well-known provider of data on the airline industry. For each route that North Air flies, I obtained monthly data on the number of flights and seats offered by the airline, as well as by all the rival carriers that operated in the same route-month. Table 2 presents summary statistics on the competition variables that I use from the OAG. It shows the number of carriers, seats and flightsseparately for North Air and all of its rivals - on each route-month on which North Air provided service. The average number of rivals was 1.89 , which ranged from 0 (on certain holiday destination routes) to 5 (Toronto-New York). Rivals operated around 415 flights a month on these routes, with about 37,000 available seats on average. North Air itself operated about 150 flights a month with approximately 10,000 seats, showing that the airline operated about the same number of flights as its rivals, but with smaller planes on average. I 
Table 2: Summary Statistics: OAG Data

\begin{tabular}{lccccc}
\hline & Mean & SD & Min. & Median & Max. \\
\hline Rival Carriers & 1.89 & 1.00 & 0 & 2 & 5 \\
Rival Seats & 37461 & 40220 & 0 & 19572 & 157119 \\
Rival Flights & 415.0 & 385.4 & 0 & 236 & 1682 \\
Own Seats & 10444 & 8727 & 127 & 7560 & 38220 \\
Own Flights & 147.6 & 123.3 & 2 & 107 & 546 \\
HHI Seats & 0.46 & 0.16 & 0.22 & 0.45 & 1.00 \\
HHI Flights & 0.47 & 0.17 & 0.21 & 0.44 & 1.00 \\
\hline
\end{tabular}

Note: An observation is a route-month. $\mathrm{N}=2144$.

also calculated the Herfindahl-Hirschmann Index of competition on these routes, based both on seats and flights. This index had a mean of 0.46 , and ranged from 0.21 to 1 .

\section{Model}

In this section I present a simple model of a firm that sets price menus over time, to a changing composition of consumers. Average price differences over time will reflect differences in the willingness-to-pay of consumers for a given quality level. Price differences for different quality levels, at a given point in time, represent second-degree price discrimination.

The model can help us understand how the practice of inter-temporal discrimination affects a firm's ability to extract profits through quality-based discrimination and vice versa. One possibility is that consumers' preferences are correlated, so that those who have a greater taste for quality, for example, may also have greater willingness-to-pay for a given quality level. This would allow firms to extract greater surplus from consumers, implying that the two kinds of discriminatory pricing may reinforce each other. Conversely, it may be the case that it is becomes harder to extract surplus from, say, group pricing, once the firm has implemented menu pricing, or vice versa. This may be because there may be limits on the total willingness-to-pay of consumers, and so the two types of discriminatory pricing may offset each other.

I consider a model of a firm that engages in both kinds of discriminatory pricing. This is related to models of multi-dimensional screening, and it is well known that these models can be difficult to solve. However, I can simplify the model by considering the specific case of the airline industry and relying on two key characteristics of my setting.

First, I assume that the willingness-to-pay of consumers increases, on average, over time. Moreover, this fact is known to consumers themselves, and therefore they correctly understand that equilibrium prices will rise, in expectation, over time as well. As a result, 
consumers buy immediately once their personal uncertainty regarding travel is resolved. There is no point waiting to buy in a later period, since prices are only expected to increase.

Second, I assume that the firm has unconstrained inventory, though it incurs some constant marginal cost of providing service. Abstracting away from the inventory management problem simplifies the analysis considerably, and allows me to focus on the interaction of the two kinds of price discrimination. Moreover, this assumption also fits well with the empirical results of Section 5, which show that remaining inventory does not affect price discrimination.

Assume that there are two periods. Period 1 is the advance purchase period and Period 2 is the last-minute purchase period. In each period $t$, consumer types are drawn from a distribution function $F_{t}(\theta)$, with support $[\underline{\theta}(t), \bar{\theta}(t)]$. Thus, the distribution functions are allowed to differ across the two periods, reflecting the fact that the composition of traveller types may change over time. In addition, the support of the distribution potentially varies across the two periods, reflecting the possibility that later arriving consumers may have higher average willingness-to-pay. I use $f_{1}()$ and $f_{2}()$ to denote the density functions for the distribution functions $F_{1}()$ and $F_{2}()$ respectively.

In each period, the firm can offer both low and high quality seats, at a constant marginal cost of $c_{L}$ and $c_{H}$ respectively. The firm must choose prices, $p_{L}$ and $p_{H}$, in each period to maximize profits. Given that consumers do not have a strategic reason to delay purchasing, and there are no inventory constraints, the firm's pricing decisions in the two periods are completely independent; in other words we can think of this as a pair of one-period problems.

A consumer of type $\theta$ gets a utility of $\theta$ from consuming the low-quality ticket, and $\phi \theta$ from consuming the high quality version, where $\phi>1$. Thus $\phi-1$ is a measure of the difference in quality between the two goods. A necessary condition for an equilibrium is:

$$
c_{H}-c_{L}<\phi-1
$$

In other words, the marginal cost increase of providing high-quality service over low-quality service must be less than the marginal willingness-to-pay for high-quality versus low-quality service.

In each period $t$, let $\theta_{1}(t)$ denote a consumer who is indifferent between the low quality ticket and not purchasing a ticket at all. Then the Individual Rationality constraint requires:

$$
\theta_{1}(t)-p_{L}(t)=0
$$

which implies that $\theta_{1}(t)=p_{L}(t)$. Let $\theta_{2}(t)$ denote a consumer who is indifferent between the low quality ticket and the high quality ticket in each $t$. Then the Incentive Compatibiity 
constraint requires:

$$
\phi \theta_{2}(t)-p_{H}(t)=\theta_{2}(t)-p_{L}(t)
$$

which implies that

$$
\theta_{2}(t)=\frac{p_{H}(t)-p_{L}(t)}{\phi-1}
$$

Suppressing time subscripts, we can write the firm's problem in each period as choosing prices to maximize profits:

$$
\max _{p_{L}, p_{H}}\left\{\left[F\left(\theta_{2}\right)-F\left(\theta_{1}\right)\right]\left[p_{L}-c_{L}\right]+\left[1-F\left(\theta_{2}\right)\right]\left[p_{H}-c_{H}\right]\right\}
$$

The first order condition with respect to $p_{L}$ is:

$$
\left[F\left(\theta_{2}\right)-F\left(\theta_{1}\right)\right]+\left(p_{L}-c_{L}\right)\left[\frac{-f\left(\theta_{2}\right)}{\phi-1}-f\left(\theta_{1}\right)\right]+\left(p_{H}-c_{H}\right) \frac{f\left(\theta_{2}\right)}{\phi-1}=0
$$

which simplifies to:

$$
\left(p_{H}-c_{H}\right) f\left(\theta_{2}\right)+(\phi-1)\left[F\left(\theta_{2}\right)-F\left(\theta_{1}\right)\right]=\left(p_{L}-c_{L}\right)\left[f\left(\theta_{2}\right)+f\left(\theta_{1}\right)(\phi-1)\right]
$$

The first order condition with respect to $p_{H}$ is:

$$
\left(p_{L}-c_{L}\right) \frac{f\left(\theta_{2}\right)}{\phi-1}+\left[1-F\left(\theta_{2}\right)\right]=\left(p_{H}-c_{H}\right) \frac{f\left(\theta_{2}\right)}{\phi-1}
$$

which simplifies to:

$$
\left(p_{L}-c_{L}\right) f\left(\theta_{2}\right)+(\phi-1)\left[1-F\left(\theta_{2}\right)\right]=\left(p_{H}-c_{H}\right) f\left(\theta_{2}\right)
$$

Combining the two first order conditions, (2) and (3), we get:

$$
p_{L}=c_{L}+\frac{\left[1-F\left(p_{L}\right)\right]}{f\left(p_{L}\right)}
$$

and

$$
p_{H}-p_{L}=c_{H}-c_{L}+\frac{(\phi-1)\left[1-F\left(\frac{p_{H}-p_{L}}{\phi-1}\right)\right]}{f\left(\frac{p_{H}-p_{L}}{\phi-1}\right)}
$$

As a benchmark, consider the case where $F(\theta)$ is uniform in each period. Then, equations 4 and 5 imply the following optimal prices:

$$
p_{L}(t)=\frac{\bar{\theta}(t)+\max \left[\underline{\theta}(t), c_{L}\right]}{2}
$$




$$
p_{H}(t)=\frac{\phi \bar{\theta}(t)+\max \left[\phi \underline{\theta}(t), c_{H}\right]}{2}
$$

The interesting question is whether the premium for high-quality service changes over time. Examining equations 6 and 7 we can see that the change in the premium depends on the evolution of the support of consumer types. For example, if $\bar{\theta}$ is increasing in $t$ but $\underline{\theta}$ is not, then $p_{H}$ increases faster than $p_{L}$ and the quality premium grows over time.

By contrast, it is possible for the quality premium to shrink over time. This happens if, for example, if $\underline{\theta}$ is increasing in $t$ but $\bar{\theta}$ is not. In such a case, for parameter values that satisfy $c_{L}<\underline{\theta}<c_{H}$, the low-quality price increases over time while the high-quality price does not.

Now consider a more general distribution of consumer types. In particular, the distribution of $\theta$ can be different in Periods 1 and 2. Specifically, the mass of the distribution can be weighted more or less heavily towards higher types in the second period, compared to the first. I state the following proposition:

Proposition 1. If the hazard rate of the distribution of consumer types increases over time then the premium for high quality decreases over time and vice versa.

Proof. As the hazard rate of any distribution is defined as the ratio of the probability density function to the survival function, $\frac{f(\theta)}{[1-F(\theta)]}$, the proof of the proposition is evident from examining Equation 5, which shows that the relative premium for higher quality is a decreasing function of the hazard rate of the distribution of consumer types.

Figure 2 shows the relationship between the hazard rates and densities for three different Beta distributions on the interval $[0,1]$. Panel (a) shows the probability density functions; the solid black curve depicts a symmetric Beta distribution, while the dashed blue and (thicker) dashed red curves depict right- and left-skewed Beta distributions respectively. A right-skewed (or positive-skewed) Beta distribution, for example, has more weight on lower values. Panel (b) of the figure shows the survival functions for each distribution, which are just the complements of the probability distribution functions, $1-F(x)$. Finally, Panel (c) shows the hazard functions, which are the ratio of each density function to its survivor function. As can be seen, the right-skewed Beta distribution has a higher hazard rate, for any value along the support, than the symmetric distribution, which in turn has a higher hazard rate than the left-skewed distribution.

Proposition 1, therefore, implies that the evolution of prices over time depends on the arrival rate of consumers in each period and, in particular, whether consumers with a greater taste for quality are over- or under-represented in the last-minute purchase period compared to the advance purchase period. For example, if later arriving consumers are more likely 
Figure 2: Densities, Survival Functions and Hazard rates

(a) Densities

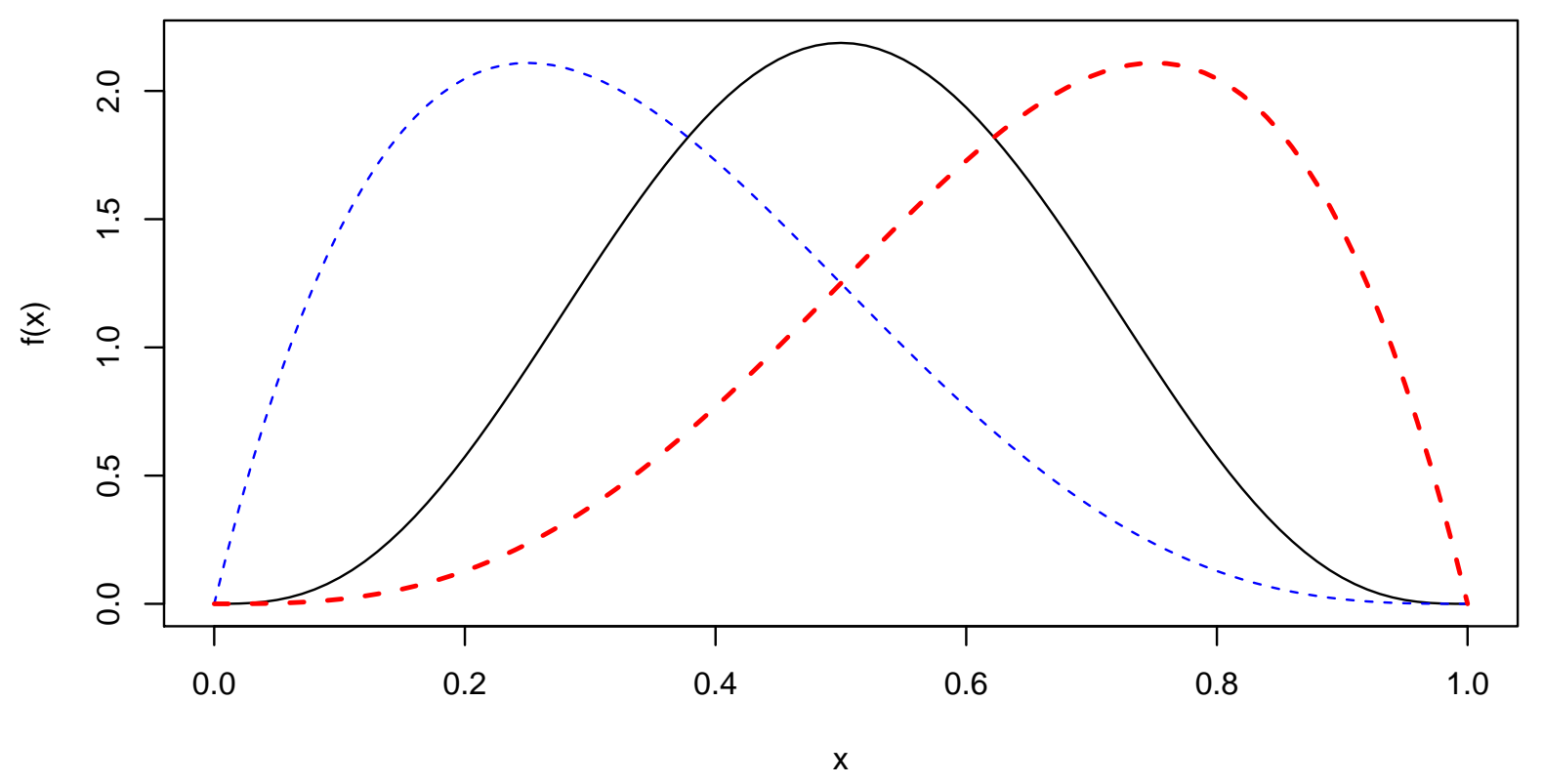

(b) Survival Functions

(c) Hazard Rates
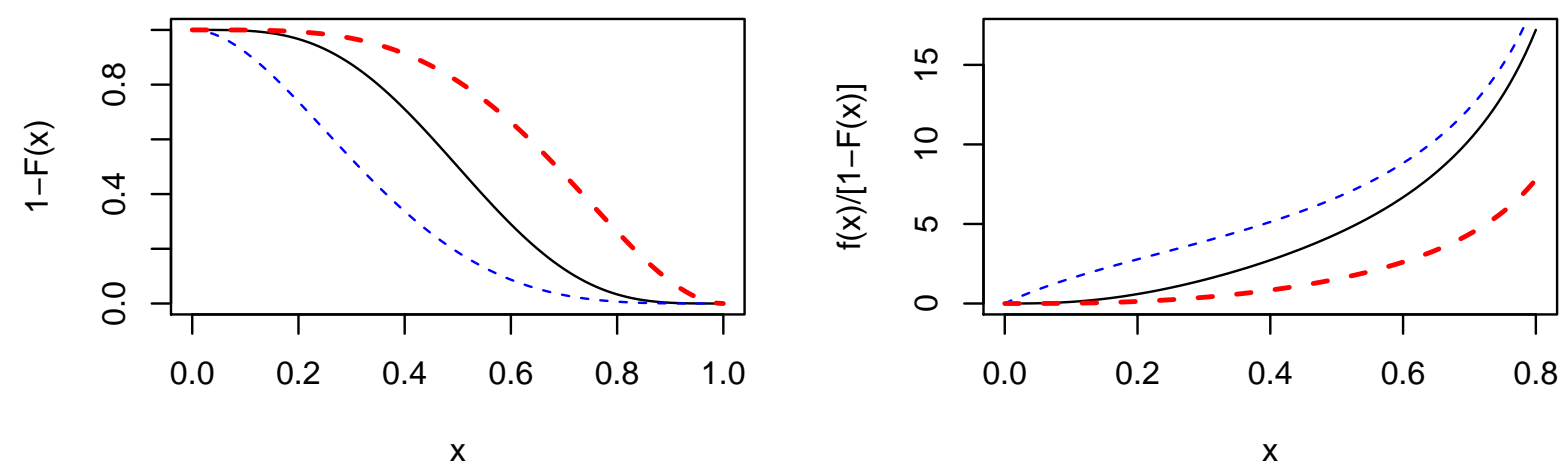
than earlier arrivals to have a greater taste for quality, then we should expect to see the premium for higher quality to grow over time. By contrast, if later arriving consumers are have a relatively lower taste for quality than their counterparts in the first period, the quality premium will shrink over time.

To see this more clearly, and to also understand how equilibrium market shares depend on the arrival rate of consumers, it is helpful to consider numerical simulations, allowing for the willingness-to-pay of consumers to increase over time.

I assume that in period 1 , consumer types are drawn on $[0,1]$, while in period 2 , consumer types are drawn on $[1,2]$. Thus, the support of the Period 2 distribution is just shifted to the right by a constant, reflecting the higher average willingness to pay by consumers who arrive later. Given the cost condition in Equation 1, I assume that $c_{H}-c_{L}=\frac{\phi-1}{2}$. Finally, I assume that consumer types in each period follow a Beta distribution, with parameters $\alpha$ and $\beta$. I consider three cases:

Case 1: Symmetric Beta distribution in both periods: $\theta \sim \beta(2,2)$. This implies that the density is given by $f(\theta)=6 \theta(1-\theta)$ and the distribution function is $F(\theta)=3 \theta^{2}-2 \theta^{3}$. Then, equations 4 and 5 imply:

$$
8 p_{L}^{3}-9 p_{L}^{2}+1=0
$$

which implies that, in period $1, p_{L}=0.42$ and $p_{H}=0.68(\phi-1)+p_{L}$.

In period 2, the distribution shifts to $[1,2]$. Everything stays the same if we simply define $\tilde{\theta}=\theta-1$. Then the period 2 prices are $p_{L}=0.42+1$ and $p_{H}=0.68(\phi-1)+p_{L}$. So the premium for high quality fares stays constant over time and equals $0.68(\phi-1)$.

Case 2: I continue to assume a symmetric Beta distribution in Period $1, \theta \sim \beta(2,2)$, but now a negative-skewed (left-skewed) Beta distribution in Period 2: $\theta \sim \beta(3,2)$. This implies that the density is given by $f(\theta)=12 \theta^{2}(1-\theta)$ and the distribution function is $F(\theta)=4 \theta^{3}-3 \theta^{4}$.

In other words, the distribution shifts to having relatively more high types in period 2. In this case, the premium for high fares increases over time, from $0.68(\phi-1)$ to $0.70(\phi-1)$.

Case 3: As before, I assume a symmetric Beta distribution in Period 1, $\theta \sim \beta(2,2)$, but now a positive-skewed (right-skewed) Beta distribution in Period 2: $\theta \sim \beta(2,3)$. This implies that the density is given by $f(\theta)=12 \theta(1-\theta)^{2}$ and the distribution function is $F(\theta)=6 \theta^{2}+3 \theta^{4}-8 \theta^{3}$.

In other words, the distribution shifts to having relatively more low types in period 2. In this case, the premium for high fares decreases over time, from $0.68(\phi-1)$ to $0.64(\phi-1)$.

The density functions for each of the three cases, and the corresponding price paths are shown in Figure 3 for a given value of $\phi$. The top panel depicts Case 1, where the distribution of consumer types is symmetric in each period, and therefore the premium for 
Figure 3: The arrival rate of consumer types and the evolution of the price premium over time
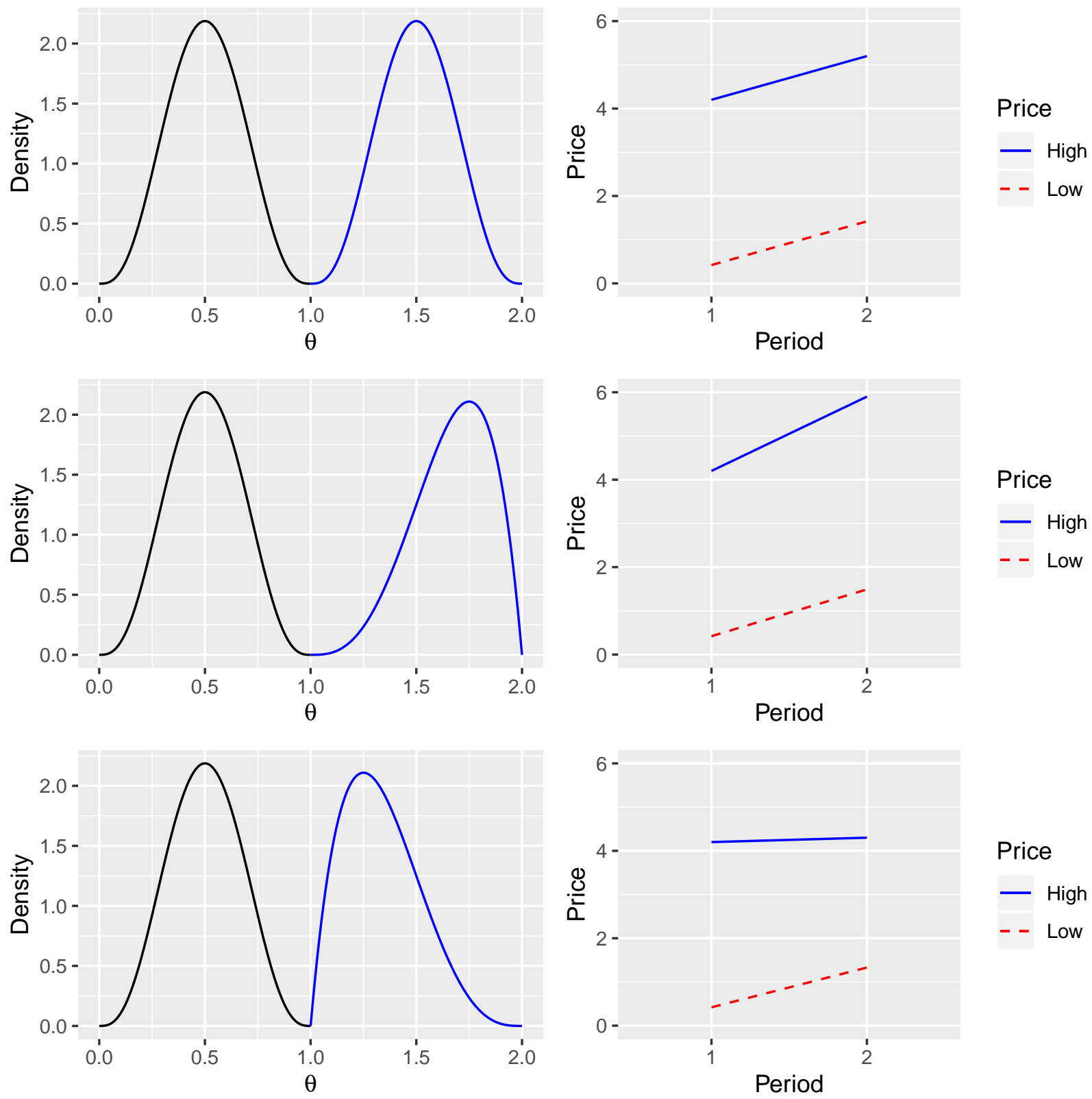
Table 3: Numerical Solutions for Period 2 shares and quality premium

\begin{tabular}{lcccc}
\hline Case & $\theta_{1}$ & $\theta_{2}$ & $\frac{1-\theta_{2}}{1-\theta_{1}}$ & $p_{H}-p_{L}$ \\
\hline 1 & 0.42 & 0.68 & 0.55 & $0.68(\phi-1)$ \\
2 & 0.49 & 0.70 & 0.58 & $0.70(\phi-1)$ \\
3 & 0.33 & 0.64 & 0.53 & $0.64(\phi-1)$ \\
\hline
\end{tabular}

the high-quality version is constant over time. The middle panel depicts Case 2, where relatively more high-types arrive in Period 2, which causes the premium for the high-quality version to increase over time. The bottom panel depicts Case 3, where relatively fewer hightypes arrive in the second period, causing the high-quality premium to shrink over time.

It is also useful to examine the equilibrium share of consumers who purchase the lowversus high-quality good in each case. Table 3 presents the Period 2 equilibrium price premiums and cutoff values for $\theta_{1}$ and $\theta_{2}$. It also shows the share of consumers, ine ach case, who purchase the high-quality version in the second period, which is calculated as $\frac{1-\theta_{2}}{1-\theta_{1}}$.

As the table shows, the second period in Case 1 has the same price premium for highquality as in Period 1, and 55\% of consumers purchase the high-quality version. In Case 2 , the premium increases relative to Period 1, due to the relatively larger number of high types arriving in the second period. Despite this, the equilibrium share of consumers who purchase the high-quality version rises, to $58 \%{ }^{15}$ Analogously, in Case 3 , both the relative premium and the share of consumers purchasing the high-quality version drop, compared to Period 1.

To summarize, this model has implications for the evolution of fares over time, which will depend on the arrival rate of various consumer types. Markets where relatively more high types arrive later will see a greater divergence between the prices for low and high quality levels. By contrast, markets where fewer high types arrive late will see a shrinking of the gap between low and high quality prices over time. In equilibrium, the firm will sell relatively more high-quality seats in the later period in markets where relatively more high-types arrive in that period, and vice versa.

With these predictions from the model, I now turn to empirical results to demonstrate that there exist airline routes where the equilibrium fares and market shares show similar patterns to the cases described above.

\footnotetext{
${ }^{15}$ The intuition for this is a simple demand shift, causing both prices and quantity to rise due to the higher willingness-to-pay.
} 


\section{Results}

I now present three main types of results. First, I will establish basic facts about price discrimination in this setting, and show the existence of clear advance purchase gradients, for

both quality levels. I will also show how different markets exhibit strikingly different patterns of second-degree price discrimination, but generally similar patterns of third-degree price discrimination. Second, I will incorporate data on capacity to show that inter-temporal price differences are driven almost entirely by price discrimination, and not by scarcity pricing, thus resolving an open question in the literature. Third, I will examine how competition affects each kind of price discrimination, holding constant the other kind.

\subsection{Advance Purchase Gradients and the Quality Premium}

In this subsection I will quantify the advance purchase gradient, which is the extent to which fares vary based on how far in advance travelers purchased their tickets. I will also quantify the premium associated with the higher quality level on North Air.

Table 4 presents basic results. I regress the log of the fare, for each itinerary, on a set of indicators for how long in advance the ticket was purchased, separately for Low and High fares. The omitted category is tickets purchased more than 60 days in advance of the flight. High fares include only Adjustable fares in column 2, and include both Refundable and Adjustable fares in column 3. I include year, month, day-of-week and route fixed effects in all specifications, and cluster standard errors by route.

Two results are apparent from Table 4. First, there are clear advance purchase gradients, for both low and high quality levels. Relative to the omitted category containing itineraries purchased more than 60 days in advance, fares rise monotonically as the date of travel approaches. On average, tickets purchased within one day of travel are about $80 \%$ more expensive than tickets of the same quality level purchased more than two months in advance, whether examining low or high service levels. Second, including fully Refundable tickets in the High fare classification raises the average fare in any time period, relative to only using Adjustable tickets, but does not materially change the estimated advance purchase gradient, as can be seen by comparing coefficients across columns 2 and 3. Therefore, for all the empirical exercises that follow, I define High fares as including both Adjustable and Refundable tickets.

It is perhaps easier to see properties of the advance purchase gradients graphically. I present these gradients in Figure 4, separately for domestic travel and for transborder travel to the United States. These gradients are estimated, for each group of routes, by a single, pooled regression for low and high fares. This is to more easily compare coefficients, and 
Table 4: Regression of Fares on Advance Purchase Days: Full Sample

\begin{tabular}{lccc}
\hline & Low & High-1 & High-2 \\
\hline 0 to 1 days & $0.782^{* * *}$ & $0.811^{* * *}$ & $0.868^{* * *}$ \\
& $(0.02)$ & $(0.09)$ & $(0.10)$ \\
2 to 4 days & $0.721^{* * *}$ & $0.772^{* * *}$ & $0.812^{* * *}$ \\
& $(0.03)$ & $(0.09)$ & $(0.10)$ \\
5 to 7 days & $0.605^{* * *}$ & $0.697^{* * *}$ & $0.727^{* * *}$ \\
& $(0.03)$ & $(0.09)$ & $(0.10)$ \\
8 to 14 days & $0.402^{* * *}$ & $0.545^{* * *}$ & $0.570^{* * *}$ \\
& $(0.02)$ & $(0.06)$ & $(0.07)$ \\
15 to 21 days & $0.162^{* * *}$ & $0.308^{* * *}$ & $0.346^{* * *}$ \\
& $(0.01)$ & $(0.02)$ & $(0.02)$ \\
22 to 30 days & $0.066^{* * *}$ & $0.215^{* * *}$ & $0.246^{* * *}$ \\
& $(0.01)$ & $(0.02)$ & $(0.02)$ \\
31 to 60 days & $0.022^{* * *}$ & $0.114^{* * *}$ & $0.129^{* * *}$ \\
& $(0.00)$ & $(0.01)$ & $(0.01)$ \\
Constant & $4.345^{* * *}$ & $4.801^{* * *}$ & $4.821^{* * *}$ \\
& $(0.04)$ & $(0.11)$ & $(0.11)$ \\
\hline $\mathrm{R}^{2}$ & 0.447 & 0.379 & 0.343 \\
Obs & 736409 & 116486 & 129083 \\
\hline
\end{tabular}

${ }^{*} p<0.1,{ }^{* *} p<0.05,{ }^{* * *} p<0.01$. All regressions include route, day-of-week, month and year FEs. Standard errors, clustered by route, in parentheses. High-1 refers to using only Adjustable tickets; High-2 refers to using both Adjustable and Refundable tickets. 
Figure 4: Advance Purchase Gradients for Domestic and Transborder Routes

(a) Domestic Routes

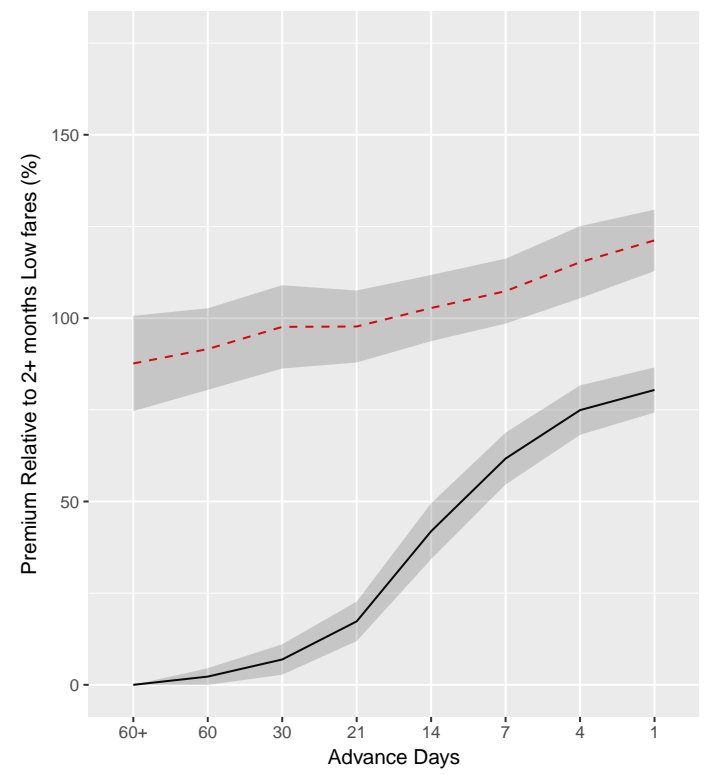

(b) Transborder Routes

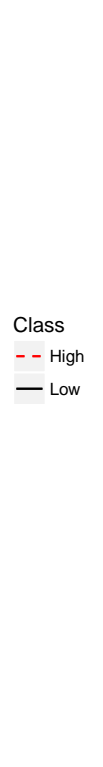

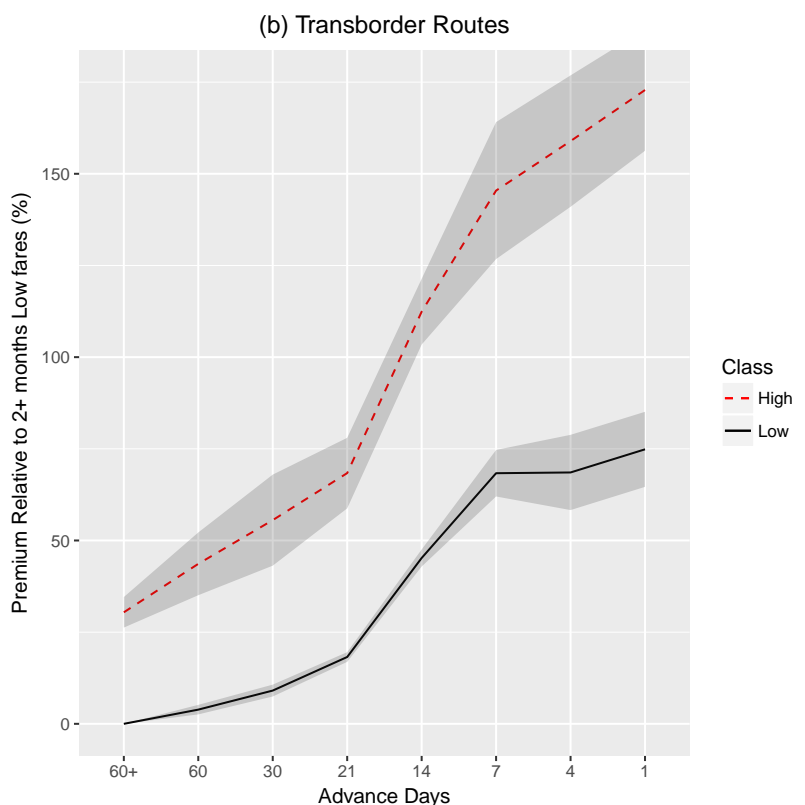

Notes: The figure plots advance purchase gradients, separately for Low and High fares, for select domestic and transborder routes. Shaded areas represent $95 \%$ confidence intervals, using standard errors clustered by route.

quality premiums, between low and high fares. ${ }^{16}$ In each panel, the coefficient for Low fares purchased more than two months is advanced is normalized to zero, and all other coefficients are expressed as relative premiums to those fares.

Figure 4 shows that, as before, both low and high fares rise monotonically as the date of travel approaches. However, the advance purchase gradients are different for low and high fares, and also different based on whether we examine domestic or transborder routes. For both domestic and transborder routes, the advance purchase gradient is fairly steep for Low fares, with tickets purchased within one day of travel being about $110 \%$ more expensive than those bought far in advance. ${ }^{17}$ The low fare gradients in each market follow a relatively similar shape. Even though the coefficients for tickets bought in the last 2-3 days before travel appear to look dissimilar, we cannot reject the hypothesis that they are the same, due to the wide confidence intervals for coefficients on late purchases, especially in the transborder market. ${ }^{18}$

By contrast, the domestic and transborder markets exhibit very different gradients for

\footnotetext{
${ }^{16}$ Regression coefficients are presented in Table 13 in the Appendix.

${ }^{17}$ This was obtained by calculating $\exp (0.75)-1$.

${ }^{18}$ These confidence intervals widen because relatively few tickets are sold at the last minute for low fares. This is especially true for transborder travel, likely because international travelers generally need to make plans further in advance.
} 
high fares. High fares for domestic routes exhibit only a slight gradient, with a 25 percentage point premium for tickets bought just prior to travel versus far in advance. However, high fares on transborder routes exhibit a much steeper gradient, with last-minute purchases costing well over double the price of tickets bought 60 days in advance.

These results imply that, for the domestic market, there is a convergence between high and low fares over time, whereas these fares diverge - quite sharply - in the transborder market. It is likely that this difference is related to the composition of travelers in each market. Before, turning to an explanation, I first demonstrate that these differences are very robust, and are apparent on a route-by-route basis across the two markets.

For what follows, it will be convenient to summarize the advance purchase gradientcaptured in Table 4 by the various indicators for each purchase period - in a single coefficient. One simple way to do this is to estimate the price elasticity with respect to the number of days remaining until travel. For any route $i$, I estimate the following relationship:

$$
P_{i t}=\alpha_{i} D_{t}^{\gamma_{i}}
$$

Here, $D_{t}$ denotes the days remaining until travel for a fare purchased at time $t, \alpha_{i}$ is a route-specific premium or discount, and $\gamma_{i}$ is the route-specific price elasticity with respect to the remaining days until travel. Thus, $\gamma$ captures, in a single parameter, the gradient of advance purchase discounts.

I take logs of Equation 9 and estimate elasticities for each route, or for groups of routes. In order to perform the estimation, I restrict the sample to tickets purchased within a certain period of travel, to prevent the results being distorted by outlier itineraries that are purchased many months in advance. In Table 5, I summarize these elasticities using a 60-day window of purchase, but I show in Table 14 in the Appendix that the results are almost identical using a 90-day window. ${ }^{19}$ The table presents separate elasticities for low and high fares for some selected routes. For example, the estimated daysout elasticity for low fares on the Toronto-Montreal route is -0.25 , implying that a $10 \%$ decrease in the days until travel is associated with an average price increase of around $2.5 \%$ for such fares on this route. I show the estimated elasticities for the top three domestic routes, the top three transborder routes, and then average elasticities for domestic, transborder and all routes.

The values in the left column of Table 5 are mostly very similar to each other, suggesting that the advance purchase gradient for low fares is the same across the major routes, as it is for the full sample or for subsamples of domestic and transborder flights. The average value of $\gamma$ is around 0.25, with Boston and Chicago being slight outliers, with estimated

\footnotetext{
${ }^{19}$ Tickets purchased within 60 and 90 days of travel account for $88 \%$ and $95 \%$ of itineraries, respectively.
} 
Table 5: Daysout Elasticities

\begin{tabular}{lccccc}
\hline \multirow{2}{*}{$\begin{array}{l}\text { Route (to and } \\
\text { from Toronto) }\end{array}$} & \multicolumn{2}{c}{ Low Fares } & & \multicolumn{2}{c}{ High Fares } \\
\cline { 2 - 3 } \cline { 6 - 6 } & $\gamma$ & $N$ & & $N$ \\
\hline Montreal & -0.252 & 117905 & -0.055 & 20253 \\
Ottawa & -0.272 & 125364 & -0.078 & 20213 \\
Thunder Bay & -0.207 & 32357 & & -0.082 & 2598 \\
\hline New York & -0.259 & 80285 & & -0.250 & 25326 \\
Boston & -0.307 & 26336 & & -0.519 & 11020 \\
Chicago & -0.189 & 22506 & & -0.522 & 11416 \\
\hline All Domestic & -0.257 & 389738 & -0.065 & 58098 \\
All Transborder & -0.253 & 136899 & -0.387 & 49109 \\
All Routes & -0.258 & 526637 & -0.215 & 107207 \\
\hline
\end{tabular}

Note: $\gamma$ is the estimated price elasticity with regard to days remaining until travel, for the corresponding route(s) and fare type. Estimating regressions include route, day-of-week, month and year FEs. Sample restricted to purchases made within 60 days of travel.

elasticities of 0.3 and 0.19 , respectively. Overall, though, the average elasticities for domestic and transborder travel are very similar, in line with the results in Figure 4.

However, the values in the right column exhibit wide variation, and significant differences between domestic and transborder travel. Specifically, the advance purchase gradient for high fares is considerably flatter for travel between Toronto and the other major Canadian destinations, as well as for domestic routes in the aggregate, with an elasticity of around -0.06 to -0.08. This implies that, for such routes, there is not much inter-temporal price discrimination among buyers of high-quality tickets, suggesting perhaps that there is little room to extract further surplus from such buyers once they self-select into the more expensive, flexible tickets.

On the other hand, the elasticity for high fares on the three busiest transborder routes, and for transborder routes in general, is considerably greater; as high as, or even higher than, the elasticity for Low Fares. Once again, these results are consistent with those shown in Figure 4. This suggests that those travelers on US-Canada routes who self-select into expensive tickets are also subject to extensive third-degree price discrimination by advance purchase. I will examine this suggestive evidence more deeply in the empirical analysis that follows.

I now show evidence that the share of high-quality tickets sold is significantly higher closer to the travel date on transborder routes, than it is on domestic routes, where such tickets are relatively more likely to be sold earlier. Figure 5 presents histograms of the 
Figure 5: The share of fixed and adjustable tickets on Domestic and Transborder Routes Domestic

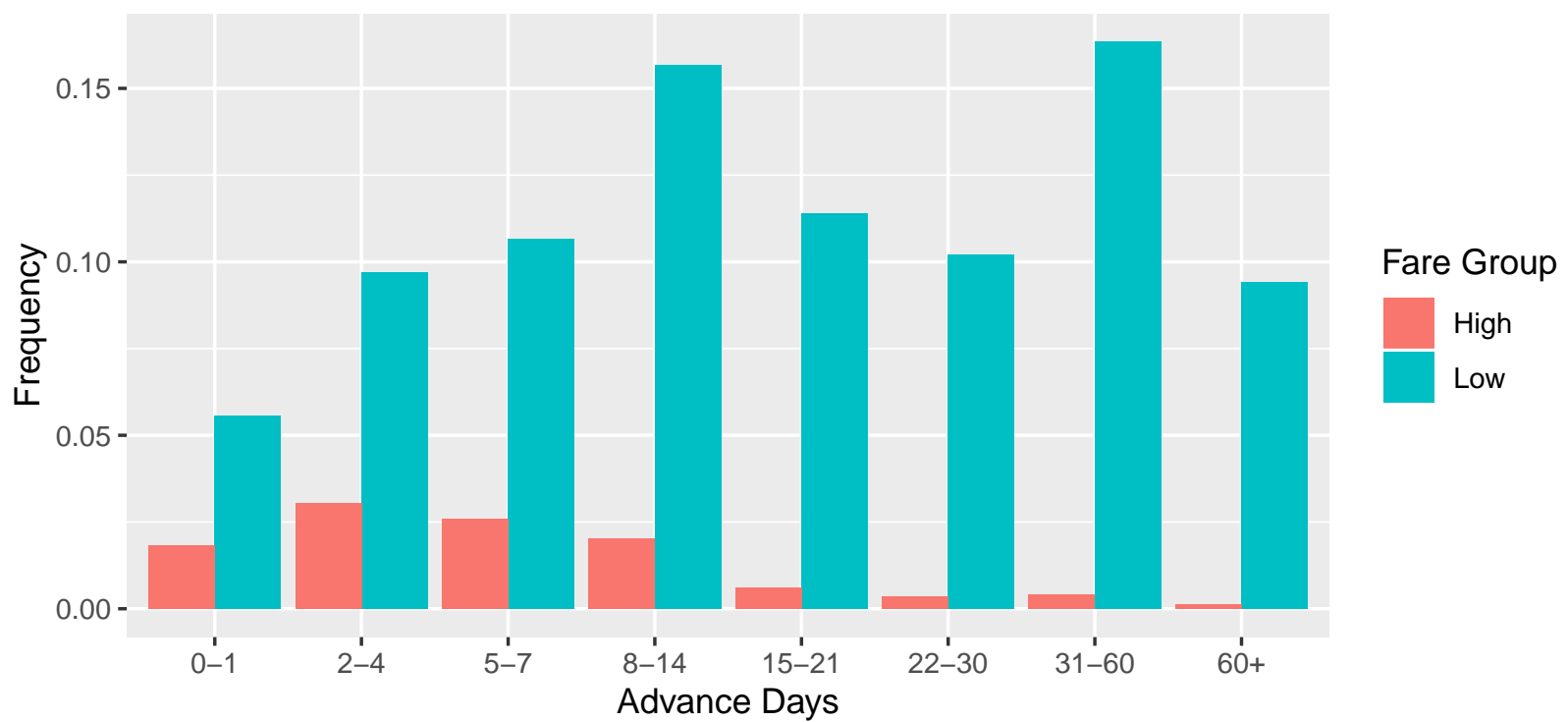

\section{Transborder}

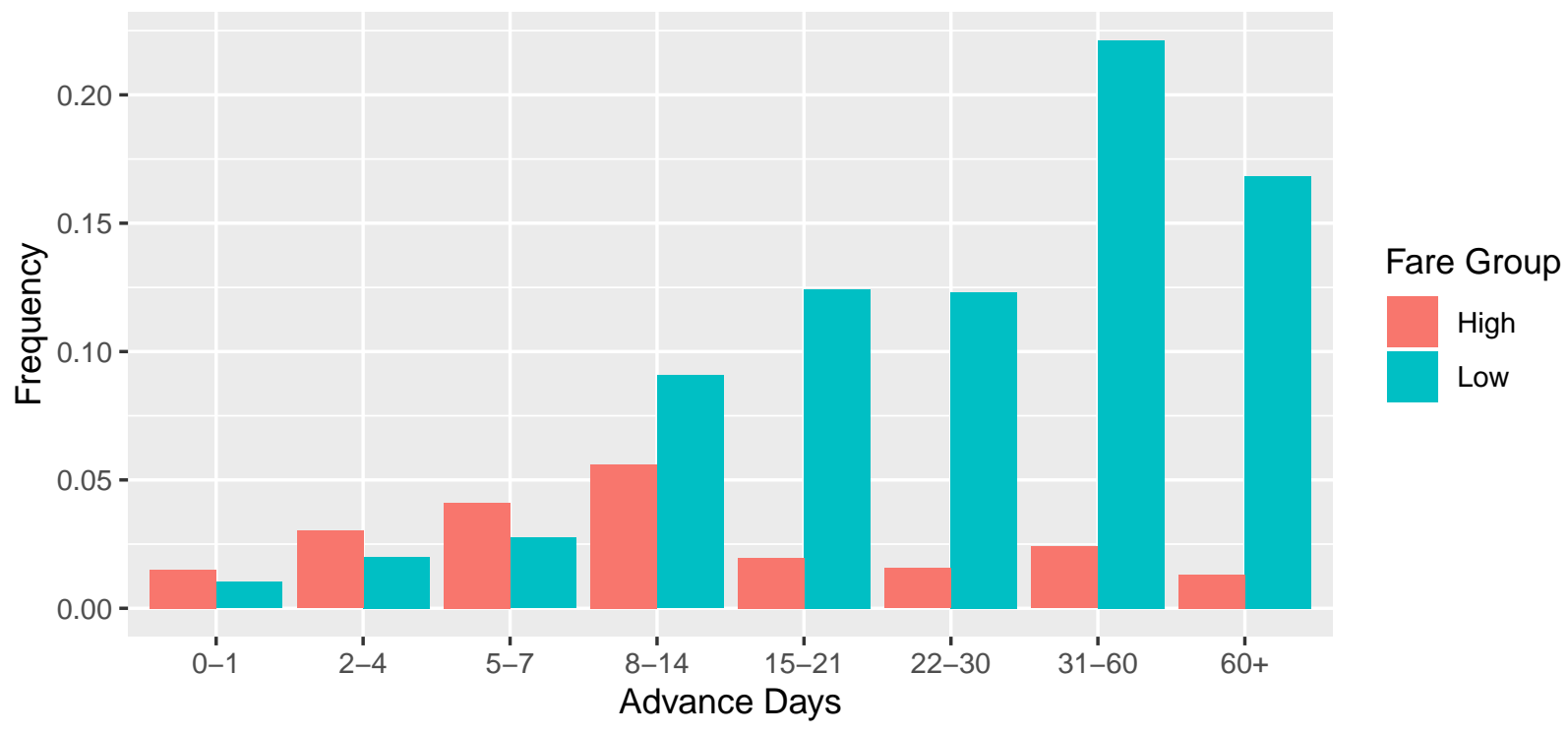

share of tickets sold in each fare group across domestic and transborder routes. Low-quality tickets comprise the vast majority of sales in general, and are most of the tickets sold in each advance date grouping on Domestic routes. However, on Transborder routes high-quality tickets make up a steadily larger share of tickets sold as the date of travel approaches, and actually outnumber the low-quality tickets in the last week of sales prior to travel. Thus, Figure 5 indicates that Transborder routes see relatively more high-quality tickets sold in later periods.

To see this more formally I present, in Table 6 probit regressions of the probability that 
Table 6: Probit Regressions of the Share of Adjustable Tickets sold

\begin{tabular}{|c|c|c|c|c|}
\hline & \multicolumn{2}{|c|}{ Transborder } & \multicolumn{2}{|c|}{ Domestic } \\
\hline & (1) & $(2)$ & (3) & $(4)$ \\
\hline 0 to 1 days & $\begin{array}{c}2.327^{* * *} \\
(0.02)\end{array}$ & & $\begin{array}{c}1.790^{* * *} \\
(0.02)\end{array}$ & \\
\hline 2 to 4 days & $\begin{array}{c}2.257^{* * *} \\
(0.02)\end{array}$ & & $\begin{array}{c}1.737 * * * \\
(0.02)\end{array}$ & \\
\hline 5 to 7 days & $\begin{array}{c}2.176^{* * *} \\
(0.02)\end{array}$ & & $\begin{array}{c}1.543^{* * *} \\
(0.02)\end{array}$ & \\
\hline 8 to 14 days & $\begin{array}{c}1.425^{* * *} \\
(0.01)\end{array}$ & & $\begin{array}{c}1.154^{* * *} \\
(0.02)\end{array}$ & \\
\hline 15 to 21 days & $\begin{array}{c}0.433^{* * *} \\
(0.01)\end{array}$ & & $\begin{array}{c}0.668^{* * *} * \\
(0.02)\end{array}$ & \\
\hline 22 to 30 days & $\begin{array}{c}0.286^{* * *} \\
(0.02)\end{array}$ & & $\begin{array}{c}0.416^{* * *} \\
(0.02)\end{array}$ & \\
\hline 31 to 60 days & $\begin{array}{c}0.182^{* * *} \\
(0.01)\end{array}$ & & $\begin{array}{c}0.244^{* * * *} \\
(0.02)\end{array}$ & \\
\hline$\gamma$ & & $\begin{array}{c}-0.751^{* * *} \\
(0.00)\end{array}$ & & $\begin{array}{c}-0.468^{* * *} \\
(0.00)\end{array}$ \\
\hline Constant & $\begin{array}{c}-1.179^{* * *} \\
(0.03)\end{array}$ & $\begin{array}{c}1.827^{* * *} \\
(0.03)\end{array}$ & $\begin{array}{c}-2.384^{* * *} \\
(0.03)\end{array}$ & $\begin{array}{c}-0.240^{* * *} \\
(0.03)\end{array}$ \\
\hline $\mathrm{R}^{2}$ & & & & \\
\hline Obs & 223491 & 223491 & 493646 & 493646 \\
\hline
\end{tabular}

Note: An observation is an itinerary. All regressions include year, month, day-of-week and route fixed-effects.

a ticket is high-quality on measures of advance purchase duration, separately for Domestic and Transborder routes. These regressions control for a full-set of year, month, day-of-week and route fixed-effects. Comparing columns 1 and 3, we can see that Transborder markets are more likely than Domestic routes to sell-high quality tickets in the two weeks prior to travel, but that the reverse is true further in advance. Comparing columns 2 and 4, we see that the likelihood of a ticket being high-quality drops off much faster with the days until travel for Transborder routes than for Domestic ones. Overall, these results clearly show that high-quality tickets are disproportionately sold in later periods on Transborder routes.

Taken together, the results of Tables 5 and 6 show results that are fully consistent with the model presented in Section 4: that it is possible for the low- and high-quality prices to either diverge or converge over time, i.e. that temporal price discrimination can either offset or reinforce quality-based price discrimination. Specifically, on domestic routes the premium for high-quality service shrinks as the date of travel approaches, while on transborder routes the opposite is true. Moreover, domestic routes are relatively less likely than transborder 
Table 7: Regression of Fares on Both Kinds of Price Discrimination

\begin{tabular}{|c|c|c|c|c|c|}
\hline & \multicolumn{3}{|c|}{ All Routes } & \multirow{2}{*}{$\begin{array}{c}\text { Transborder } \\
(4)\end{array}$} & \multirow{2}{*}{$\begin{array}{c}\text { Domestic } \\
(5)\end{array}$} \\
\hline & (1) & $(2)$ & (3) & & \\
\hline$\gamma$ (Gradient) & $\begin{array}{c}-0.303^{* * *} \\
(0.01)\end{array}$ & & $\begin{array}{c}-0.241^{* * *} \\
(0.01)\end{array}$ & $\begin{array}{c}-0.210^{* * *} \\
(0.01)\end{array}$ & $\begin{array}{c}-0.242^{* * *} \\
(0.01)\end{array}$ \\
\hline High Fares & & $\begin{array}{c}0.832^{* * *} \\
(0.04)\end{array}$ & $\begin{array}{c}0.574^{* * *} \\
(0.11)\end{array}$ & $\begin{array}{c}1.155^{* * *} \\
(0.16)\end{array}$ & $\begin{array}{c}0.272^{* * *} \\
(0.04)\end{array}$ \\
\hline$\gamma * H i g h$ & & & $\begin{array}{l}0.008 \\
(0.05)\end{array}$ & $\begin{array}{c}-0.190^{* * *} \\
(0.05)\end{array}$ & $\begin{array}{c}0.161^{* * *} \\
(0.02)\end{array}$ \\
\hline Constant & $\begin{array}{c}5.461^{* * *} \\
(0.04)\end{array}$ & $\begin{array}{c}4.528^{* * *} \\
(0.03)\end{array}$ & $\begin{array}{c}5.209^{* * *} * \\
(0.03)\end{array}$ & $\begin{array}{c}5.135^{* * *} \\
(0.08)\end{array}$ & $\begin{array}{c}5.187^{* * *} \\
(0.02)\end{array}$ \\
\hline $\mathrm{R}^{2}$ & 0.424 & 0.357 & 0.546 & 0.614 & 0.536 \\
\hline $\begin{array}{l}\mathrm{R}^{2} \text { excl. } \gamma \\
\text { Obs }\end{array}$ & $\begin{array}{c}0.087 \\
697911\end{array}$ & 697911 & 697911 & 216314 & 481597 \\
\hline
\end{tabular}

routes to sell high-quality tickets close to the date of travel, which is consistent with a relatively larger share of high-type consumers arriving at the last minute on transborder routes. These differences are consistent with the notion that business and corporate travelers on transborder routes are much more likely to plan travel at the last minute than those on domestic routes.

One final exercise shows how pooling together all markets can lead to incorrect conclusions. In Table 7 I regress fares on both measures of discriminatory pricing together-the gradient of fares measuring temporal price discrimination, and an indicator for high-quality tickets, as well as the interaction of these. The gradient, by itself, explains about $42 \%$ of the variation in fares, while the high-quality indicator explains about 35\%. Column 3 suggests that the interaction of these is not statistically significant, implying that neither measure of price discrimination is affected by the other. However, these results bely the true relationship; when I break up the sample into transborder and domestic routes, I estimate a negative interaction in the former and a positive interaction in the latter, both of which are highly statistically significant. The results suggest that the negative gradient with respect to advance purchase is particularly pronounced for high quality tickets on transborder routes, but mitigated for such tickets on domestic routes, completely in line with the results already shown in Table 5 and Figure 4. 


\subsection{Controlling for Remaining Capacity}

I now control for remaining capacity at the time of booking each itinerary, using data on flights and seats from the OAG. I restrict the sample to include only non-stop itineraries, since it is not straightforward to construct measures of remaining seats for tickets that involve a change of plane. This reduces the sample to 718,691 observations, which is approximately $83 \%$ of the number of observations in the full sample. I then construct, for each flight-day, a measure of the total number of available seats. I do this by obtaining OAG data on the number of available seats for each route-month that North Air operates. I then divide this measure by 30 to obtain the approximate daily number of available seats. ${ }^{20}$

Next, I sum up the number of tickets that North Air sold for each flight-day, and multiply these by 10 to account for the fact that I have a $10 \%$ sample of tickets. I can then calculate two measures of inventory or capacity. First, I construct the fraction of remaining seats for any purchased itinerary, which is the share of the flight's seats that are available for purchase after each ticket is purchased. Second, I construct the load factor for each flight-day, which is simply the share of available seats that are in fact occupied. Clearly, both measures are constructed with error, both because I average monthly OAG data to construct daily measures of available seats, and because of the use of a $10 \%$ sample. However, the error is mean zero, and there is no reason to believe it is correlated with pricing.

Table 8 presents summary statistics on the number of available, occupied and remaining seats, the total number of passengers on a flight, and the load factor. Note that the fraction of remaining seats varies across purchased tickets on a given flight-day, whereas load factors are constant within a flight-day. The Table shows that the average load factor for North Air flights is $48 \%$, which fits very well with industry observations about North Air, with estimated load factors of around $50 \%$ which is noticeably below average load factors for the industry. The average itinerary is purchased when about $75 \%$ of seats on a flight remain available, and this varies from zero to one across the distribution of purchased tickets.

I now employ the two constructed measures of capacity - the fraction of remaining seats and the load factor - in regressions of fares on advance purchase indicators. The results are in Table 9 and are presented separately for low and high fares. I first present, in Columns 1 and 4, regressions analogous to those in Table 4, except that I replace the discrete measures of daysout with the elasticity $\gamma$. For both types of fares, the estimated gradient is negative and similar to the average values presented in Table 5 . The results on the capacity measures show that average fares do respond to changes in remaining inventory. The coefficients on remaining seats in Columns 2 and 5 are negative, suggesting that fares are lower for itineraries

\footnotetext{
${ }^{20}$ There is likely to be day-to-day variation as, for example, the airline may operate fewer flights on weekend days. However, these differences will be captured by the day-of-week fixed effects.
} 
Table 8: Summary Statistics: Capacity Measures

\begin{tabular}{lccccc}
\hline & Mean & SD & Min. & Median & Max. \\
\hline Total Passengers & 297.2 & 189.2 & 10 & 270 & 1030 \\
Available Seats & 624.3 & 331.6 & 12 & 628 & 1274 \\
Occupied Seats & 154.4 & 139.0 & 10 & 110 & 1030 \\
Remaining Seats (\%) & 0.75 & 0.18 & 0.00 & 0.78 & 0.99 \\
Load Factor (\%) & 0.48 & 0.19 & 0.01 & 0.47 & 1.00 \\
\hline
\end{tabular}

Note: An observation is an itinerary. $\mathrm{N}=718691$.

Table 9: Regression of Fares on Advance Purchase Days: Capacity Measures

\begin{tabular}{lccccccc}
\hline & \multicolumn{3}{c}{ Low Fares } & & \multicolumn{3}{c}{ High Fares } \\
\cline { 2 - 3 } \cline { 6 - 7 } & $(1)$ & $(2)$ & $(3)$ & & $(4)$ & $(5)$ & $(6)$ \\
\hline$\gamma$ (Gradient) & $-0.236^{* * *}$ & $-0.236^{* * *}$ & $-0.237^{* * *}$ & & $-0.220^{* * *}$ & $-0.220^{* * *}$ & $-0.221^{* * *}$ \\
Remaining Seats (\%) & $(0.01)$ & $(0.01)$ & $(0.01)$ & & $(0.04)$ & $(0.04)$ & $(0.04)$ \\
& & $-0.074^{* * *}$ & & & $-0.066^{* * *}$ & \\
Load Factor (\%) & & $(0.01)$ & & & $(0.02)$ & \\
& & & $0.160^{* * *}$ & & & $0.159^{* * *}$ \\
Constant & & & $(0.02)$ & & & $(0.03)$ \\
& $5.193^{* * *}$ & $5.248^{* * *}$ & $5.118^{* * *}$ & & $5.804^{* * *}$ & $5.852^{* * *}$ & $5.723^{* * *}$ \\
$\mathrm{R}^{2}$ & $(0.03)$ & $(0.03)$ & $(0.03)$ & $(0.07)$ & $(0.08)$ & $(0.06)$ \\
$\mathrm{R}^{2}$ excl. $\gamma$ & 0.409 & 0.409 & 0.412 & & 0.328 & 0.329 & 0.331 \\
Obs & 0.153 & 0.153 & 0.155 & & 0.160 & 0.161 & 0.162 \\
\hline
\end{tabular}

$* p<0.1,{ }^{* *} p<0.05,{ }^{* * *} p<0.01$. All regressions include route, day-of-week, month and year FEs. Standard errors, clustered by route, in parentheses.

purchased when a greater fraction of seats on the flight-day remain available. Additionally, the results in Columns 3 and 6 imply that fares are higher for flight-days with higher load factors, i.e. for flight-days that have a higher ex post likelihood of being sold out.

However, the interesting result of Table 9 is that temporal variation in prices appears to be driven entirely by price discrimination, and not by variation in remaining capacity. Controlling for the fraction of remaining seats, in columns 2 and 5 , or for the load factor, in columns 3 and 6 , has no discernible effect on the advance purchase elasticity. This can be seen by the small change in the magnitude of $\gamma$ when going from column 1 to columns 2 and 3 , or from column 4 to columns 5 and 6 . Thus, these results suggest that, while remaining capacity does affect average fares, it has almost no effect in determining the temporal variation in fares of either high or quality tickets. The existence of an almost identical advance purchase gradient, even when controlling for remaining capacity or load factors, suggests that price discrimination, rather than scarcity pricing, is the main driver of intertemporal price variation. 
Additionally, the advance purchase gradient explains a considerable portion of the variation in fares, while capacity measures do not. This can be seen by examining the $R^{2}$ measures of fit at the bottom of Table 9. I present the overall $R^{2}$, as well as the $R^{2}$ obtained from each regression excluding the advance purchase gradient, i.e. the portion of variation in the dependent variable explained purely by the fixed effects. The fixed-effects alone explain about $15 \%$ of the variation in the Low fares, as seen in column 1, and this is virtually unchanged when adding the two capacity measures in columns 2 and 3. By contrast, adding the daysout elasticity raises the $R^{2}$ from $15 \%$ to $41 \%$ for low fares, and from $16 \%$ to around $33 \%$ for high fares.

As a robustness check, in Table 12 in the Appendix, I divide the sample into quartiles of the load factor, and estimate the daysout elaslticity for each quartile. The estimated elasticities are generally very similar to the one estimated for the full sample, with the exception that the gradient for the top quartile - i.e. for the fullest flights - is slightly lower, implying that the gradient of fares is slightly flatter for such flights.

In a further robustness check, I show in Table 15 in the Appendix, that the Table 9 results are almost exactly replicated when I replace $\gamma$, with the multiple daysout indicator variables that were originally employed in Table 4 . The various indicator variables explain about the same amount of variation as $\gamma$ alone and, once again, the various capacity measures do not affect the estimated gradient using these discrete measures.

Overall, therefore, the results of Table 9 imply that within-route variation in fares can be explained almost entirely by temporal price discrimination rather than by scarcity pricing. ${ }^{21}$ While measures of remaining capacity exhibit the correct sign on their estimated coefficients - implying that fuller flights are likely to be more expensive on average - they explain only a very small portion of the variation in fares, and do not change the estimated gradient with regard to advance purchases.

\subsection{Competition and Price Discrimination}

I now examine the role of competition in the implementation of both kinds of price discrimination. To do this, I rely on the fact that North Air faces differing levels of competition on the various routes it serves. I use three measures of competition: the number of rivals offering direct service on the route; and the Herfindahl Hirschmann Indices (HHIs) constructed based on each airline's share of seats and flights on the route.

How does competition affect practice of both second- and third-degree price discrimi-

\footnotetext{
${ }^{21}$ This refers to the portion of variation explained by the regressors. Note that the fit measures in Table 9 can obviously be further improved by adding finer indicators for advance purchase days, but that is not the goal of this paper.
} 
nation in settings where firms engage in each kind? Past empirical work has been unable to resolve this question in partial analysis of each kind of discriminatory pricing. For example, Busse and Rysman (2005) and Lin and Wang (2015) come to opposite conclusions when studying the effect of competition on second-degree price discrimination, as do Borenstein and Rose (1994) and Gerardi and Shapiro (2009) when studying third-degree discrimination. Some theoretical models show that the effects of competition can be non-monotonic, e.g. Dai et al. (2014) and Chandra and Lederman (2017). However, a consideration that has not been noted by past authors is that many firms engage in both kinds of discriminatory pricing simultaneously, so that it may be important to account for each kind when examining how competition affects the other. As Stole (2007) notes in his survey, past theoretical studiesespecially those of second-degree discrimination - have not provided consistent answers with respect to the effect of competition. ${ }^{22}$

Since I include route fixed effects, identification is obtained by comparing changes in these competition measures within routes. This alleviates the concern that differences in competition across routes are correlated with prices on those routes. However, it leaves two issues: first there may be insufficient variation in competition within a route over time to meaningfully identify the parameters of interest. And second, within-route changes in competition may still be correlated with unobserved factors affecting prices.

On the first issue, it is quite apparent that there is little variation in the number of direct rivals that North Air faces on a given route. Although some routes have experienced entry and exit during my sample period, for the most part the number of rivals does not change enough to identify the parameters of interest. I expect to rely more on the HHI measures which do, in fact, vary considerably. This is because airlines-both North Air itself and its rivals - exhibit considerable variation in the number and size of flights that they operate on a given route. This is due to factors such as seasonality, consumer demand, constraints on the size of the airline's fleet, and secular trends in airline expansion. North Air itself has steadily grown over time and its market share has correspondingly increased, thereby directly affecting the HHI measures.

On the second issue, while the route fixed effects do account for some of the endogeneity in market structure, they do not account for the possibility of within-route correlation between competition and unobserved demand side-factors. Note, though that the first-order effect of this remaining endogeneity should be on the average level of prices, rather than on the structure of prices that arises through price discrimination. It is not easily obvious why changes in market structure should be correlated with unobserved factors that affect the ratio of high and low fares (second-degree price discrimination) or the advance purchase

\footnotetext{
${ }^{22}$ For examples, see Stole (1995) and Rochet and Stole (2002).
} 
discounts offered by the airline (third-degree). I acknowledge, however, that I cannot fully rule out the possibility of such correlations, and therefore the following results should be understood with this caveat in mind.

I first examine the effect of competition on second-degree price discrimination, holding constant the advance purchase gradient. I regress fares on indicators for the advance purchase periods, an indicator for high fares, and an interaction between high fares and various measures of competition. The results are in Table 10. The competition measures have the expected signs - positive effects for the HHI measures and a negative effect on the number of rivals-but the HHI measures are imprecisely estimated. This suggests some weak evidence that competition may slightly reduce average fares. As discussed above, however, the endogenous effect of competition will be experienced most directly on the level of fares, suggesting that these coefficients should be interpreted with caution.

The interaction terms in Table 10 suggest a clearer story. These interactions are clearly negative for the HHI measures, and positive for the number of rivals, suggesting in each case that greater competition has the effect of increasing the quality premium that the airline charges for flexible tickets, in other words increasing the extent of second-degree price discrimination.

I now examine the effect of competition on third-degree price discrimination, holding constant the quality premium for high fares. In Table $11 \mathrm{I}$ show the results of regressions of fares on the interaction between the advance purchase elasticity $(\gamma)$ and the competition measures, with a separate intercept for High Fares. The results for the number of rivals are inconclusive, but the interactions with the HHI measures suggest that an increase in competition makes the advance purchase gradient steeper, in other words increasing the extent of third-degree price discrimination.

Overall, the results of this section suggest that the airline increases the extent of both second- and third-degree price discrimination when it faces more competition.

\section{Discussion and Conclusion}

Price Discrimination is a central and heavily researched topic in Industrial Organization, including both theoretical and empirical lines of inquiry, and focusing on the two major strands of second-degree and third-degree discrimination. For reasons related to complexity and data availability, however, prior authors in the literature have generally focused on just one or the other of these two kinds of practices. This may be adequate for situations where firms exclusively, or even predominantly, practice just one type of discriminatory pricing. However, with the availability of large new data sources on the behaviour, habits and 
Table 10: Effect of Competition on Second-Degree Price Discrimination

\begin{tabular}{|c|c|c|c|}
\hline & (1) & (2) & (3) \\
\hline 0 to 1 days & $\begin{array}{c}0.824^{* * *} \\
(0.03)\end{array}$ & $\begin{array}{c}0.825^{* * *} \\
(0.03)\end{array}$ & $\begin{array}{c}0.826^{* * *} \\
(0.03)\end{array}$ \\
\hline 2 to 4 days & $\begin{array}{c}0.761^{* * *} \\
(0.03)\end{array}$ & $\begin{array}{c}0.762^{* * *} \\
(0.03)\end{array}$ & $\begin{array}{c}0.762^{* * *} \\
(0.03)\end{array}$ \\
\hline 5 to 7 days & $\begin{array}{c}0.655^{* * *} \\
(0.03)\end{array}$ & $\begin{array}{c}0.656^{* * *} \\
(0.03)\end{array}$ & $\begin{array}{c}0.656^{* * *} \\
(0.03)\end{array}$ \\
\hline 8 to 14 days & $\begin{array}{c}0.455^{* * *} \\
(0.03)\end{array}$ & $\begin{array}{c}0.456^{* * *} \\
(0.03)\end{array}$ & $\begin{array}{c}0.455^{* * *} \\
(0.03)\end{array}$ \\
\hline 15 to 21 days & $\begin{array}{c}0.191^{* * *} \\
(0.02)\end{array}$ & $\begin{array}{c}0.191^{* * *} \\
(0.02)\end{array}$ & $\begin{array}{c}0.191^{* * *} \\
(0.02)\end{array}$ \\
\hline 22 to 30 days & $\begin{array}{c}0.089^{* * *} \\
(0.01)\end{array}$ & $\begin{array}{c}0.089^{* * *} \\
(0.01)\end{array}$ & $\begin{array}{c}0.088^{* * *} \\
(0.01)\end{array}$ \\
\hline 31 to 60 days & $\begin{array}{c}0.035^{* * *} \\
(0.01)\end{array}$ & $\begin{array}{c}0.035^{* * *} \\
(0.01)\end{array}$ & $\begin{array}{c}0.034^{* * *} \\
(0.01)\end{array}$ \\
\hline High Fares $=1$ & $\begin{array}{c}0.742^{* * *} \\
(0.06)\end{array}$ & $\begin{array}{c}0.693^{* * *} \\
(0.07)\end{array}$ & $\begin{array}{c}0.493^{* * *} \\
(0.05)\end{array}$ \\
\hline HHI (Seats) & $\begin{array}{l}0.427 \\
(0.31)\end{array}$ & & \\
\hline High Fares=1 × HHI (Seats) & $\begin{array}{c}-0.451^{* *} \\
(0.17)\end{array}$ & & \\
\hline HHI (Flights) & & $\begin{array}{l}0.250 \\
(0.36)\end{array}$ & \\
\hline High Fares $=1 \times$ HHI $($ Flights $)$ & & $\begin{array}{c}-0.342^{*} \\
(0.19)\end{array}$ & \\
\hline Rivals & & & $\begin{array}{c}-0.096^{* * *} \\
(0.02)\end{array}$ \\
\hline High Fares $=1 \times$ Rivals & & & $\begin{array}{c}0.028^{*} \\
(0.01)\end{array}$ \\
\hline Constant & $\begin{array}{l}4.053^{* * *} \\
(0.16)\end{array}$ & $\begin{array}{c}4.143^{* * *} \\
(0.17)\end{array}$ & $\begin{array}{c}4.464^{* * *} \\
(0.04)\end{array}$ \\
\hline $\mathrm{R}^{2}$ & 0.568 & 0.567 & 0.569 \\
\hline Obs & 738504 & 738504 & 738504 \\
\hline
\end{tabular}

${ }^{*} p<0.1,{ }^{* *} p<0.05,{ }^{* * *} p<0.01$. All regressions include route, day-of-week, month and year FEs. Standard errors, clustered by route, in parentheses. 
Table 11: Effect of Competition on Third-Degree Price Discrimination

\begin{tabular}{|c|c|c|c|}
\hline & (1) & (2) & (3) \\
\hline High Fares & $\begin{array}{c}0.590^{* * *} \\
(0.03)\end{array}$ & $\begin{array}{c}0.589^{* * *} \\
(0.03)\end{array}$ & $\begin{array}{c}0.590^{* * *} \\
(0.03)\end{array}$ \\
\hline$\gamma$ & $\begin{array}{c}-0.334^{* * *} \\
(0.03)\end{array}$ & $\begin{array}{c}-0.338^{* * *} \\
(0.03)\end{array}$ & $\begin{array}{c}-0.228^{* * *} \\
(0.02)\end{array}$ \\
\hline HHI (Seats) & $\begin{array}{r}-0.249 \\
(0.44)\end{array}$ & & \\
\hline$\gamma \times$ HHI (Seats) & $\begin{array}{c}0.218^{* * *} \\
(0.07)\end{array}$ & & \\
\hline HHI (Flights) & & $\begin{array}{r}-0.488 \\
(0.48)\end{array}$ & \\
\hline$\gamma \times$ HHI (Flights) & & $\begin{array}{c}0.235^{* * *} \\
(0.08)\end{array}$ & \\
\hline Rivals & & & $\begin{array}{c}-0.068^{* *} \\
(0.03)\end{array}$ \\
\hline$\gamma \times$ Rivals & & & $\begin{array}{r}-0.008 \\
(0.01)\end{array}$ \\
\hline Constant & $\begin{array}{c}5.309^{* * *} \\
(0.21)\end{array}$ & $\begin{array}{c}5.412^{* * *} \\
(0.21)\end{array}$ & $\begin{array}{c}5.374^{* * *} \\
(0.07)\end{array}$ \\
\hline $\mathrm{R}^{2}$ & 0.547 & 0.547 & 0.547 \\
\hline Obs & 688879 & 688879 & 688879 \\
\hline
\end{tabular}

${ }^{*} p<0.1,{ }^{* *} p<0.05,{ }^{* * *} p<0.01$. All regressions include route, day-of-week, month and year FEs. Standard errors, clustered by route, in parentheses. 
preferences of consumers, it is increasingly likely that firms will practice both simultaneously. It is far from obvious that the results of partial analysis of each type of price discrimination will extend to environments where firms practice both. Past research provides no guide to whether we should expect the two types to be substitutes or complements for each other, or whether they may be completely independent.

In this paper I examine an industry that has long used multiple price discrimination practices - airlines. I obtain new booking data directly from an airline that, to my knowledge, are the first of their kind to be used in academic research. I use these to examine both thirddegree price discrimination according to advance purchase behaviour, and second-degree price discrimination according to the quality of service that travellers select. I estimate the empirical relationship between the two practices, and then examine how competition affects each. I find that advance purchase gradients clearly exist, for both low and high quality levels, and that these are due to price discrimination rather than simply the optimal management of inventory. I show that there appears to be a tradeoff between the two kinds of price discrimination in some markets, but a complementarity between them in others. Finally, I find that competition increases the effect of both kinds of discriminatory pricing.

There are, naturally, some caveats to my results. Mainly, that I use data from a single airline, which is by no means representative of the entire airline industry. ${ }^{23}$ Nevertheless, the airline operates on competitive routes and therefore its prices, and the dynamic evolution of its fares, are likely to be similar to those of its rivals in equilibrium.

The main result of this paper-regarding the interaction of second- and third-degree price discrimination, is novel and has not been established before in other settings. This naturally raises the question of whether the results will extend to other industries that also practice multiple forms of discriminatory pricing. A few examples come to mind: book publishers, pharmaceuticals, and retail banks. In these example, firms may offer different prices to different groups of consumers, such as due to country-specific pricing, or discounts for seniors or students. At the same time, firms in these industries offer a range of service levels corresponding to different qualities. It would be interesting to study whether the findings of this paper extend to such settings.

\section{References}

Alderighi, M., M. Nicolini, and C. A. Piga (2015). Combined effects of capacity and time on fares: insights from the yield management of a low-cost airline. Review of Economics and

\footnotetext{
${ }^{23}$ Of course, it is common for research in this area to make similar allowances. For example, Alderighi et al. (2015) also use data from a single airline-Ryanair; Williams (2017) focuses purely on monopoly routes.
} 
Statistics 97(4), 900-915.

Armstrong, M. and J.-C. Rochet (1999). Multi-dimensional screening:: A user's guide. European Economic Review 43(4), 959-979.

Aryal, G. and M. F. Gabrielli (2020). An empirical analysis of competitive nonlinear pricing. International Journal of Industrial Organization 68, 102538.

Aryal, G., C. Murry, and J. W. Williams (2018). Price discrimination in international airline markets. Available at SSRN.

Asplund, M., R. Eriksson, and N. Strand (2008). Price discrimination in oligopoly: Evidence from regional newspapers*. The Journal of Industrial Economics 56(2), 333-346.

Borenstein, S. and N. L. Rose (1994). Competition and Price Dispersion in the US Airline Industry. Journal of Political Economy 102(4), 653-683.

Borzekowski, R., R. Thomadsen, and C. Taragin (2009). Competition and price discrimination in the market for mailing lists. QME 7(2), 147-179.

Busse, M. and M. Rysman (2005). Competition and price discrimination in yellow pages advertising. RAND Journal of Economics 36(2), 3784390.

Chandra, A. and M. Lederman (2017). Revisiting the relationship between competition and price discrimination. American Economic Journal: Microeconomics Forthcoming.

Clark, R. and N. Vincent (2012). Capacity-contingent pricing and competition in the airline industry. Journal of Air Transport Management 24, 7-11.

Dai, M., Q. Liu, and K. Serfes (2014). Is the effect of competition on price dispersion nonmonotonic? evidence from the us airline industry. Review of Economics and Statistics 96(1), 161-170.

Dana, J. and K. Williams (2016). Oligopoly price discrimination: The role of inventory controls.

Dana, J. D. (1998). Advance-purchase discounts and price discrimination in competitive markets. Journal of Political Economy 106(2), 395-422.

Dana, J. D. (1999). Equilibrium price dispersion under demand uncertainty: the roles of costly capacity and market structure. The RAND Journal of Economics, 632-660. 
Gale, I. L. and T. J. Holmes (1993). Advance-purchase discounts and monopoly allocation of capacity. The American Economic Review, 135-146.

Gerardi, K. S. and A. H. Shapiro (2009). Does competition reduce price dispersion? new evidence from the airline industry. Journal of Political Economy 117(1), 1-37.

Ivaldi, M. and D. Martimort (1994). Competition under nonlinear pricing. Annales d'Economie et de Statistique, 71-114.

Lazarev, J. (2013). The welfare effects of intertemporal price discrimination: an empirical analysis of airline pricing in us monopoly markets. New York University.

Leslie, P. (2004). Price discrimination in broadway theater. RAND Journal of Economics, $520-541$.

Lin, H. and I. Y. Wang (2015). Competition and price discrimination: evidence from the parking garage industry. The Journal of Industrial Economics 63(3), 522-548.

McManus, B. (2007). Nonlinear pricing in an oligopoly market: The case of specialty coffee. The RAND Journal of Economics 38(2), 512-532.

Möller, M. and M. Watanabe (2010). Advance purchase discounts versus clearance sales. The Economic Journal 120(547), 1125-1148.

Puller, S. L., A. Sengupta, and S. N. Wiggins (2009). Testing theories of scarcity pricing in the airline industry. Technical report, National Bureau of Economic Research.

Rochet, J.-C. and L. A. Stole (2002). Nonlinear pricing with random participation. The Review of Economic Studies 69(1), 277-311.

Seim, K. and V. B. Viard (2011). The effect of market structure on cellular technology adoption and pricing. American Economic Journal: Microeconomics 3(2), 221-251.

Shepard, A. (1991). Price discrimination and retail configuration. Journal of Political Economy $99(1), 30-53$.

Stole, L. A. (1995). Nonlinear pricing and oligopoly. Journal of Economics \& Management Strategy 4 (4), 529-562.

Stole, L. A. (2007). Price discrimination and competition. Handbook of industrial organization 3, 2221-2299. 
Sweeting, A. (2012). Dynamic pricing behavior in perishable goods markets: Evidence from secondary markets for major league baseball tickets. Journal of Political Economy 120(6), $1133-1172$.

Williams, K. R. (2017). Dynamic airline pricing and seat availability. Technical report, mimeo. 


\section{Appendix: Additional Tables}

Table 12: Daysout Gradients by Load Factor

\begin{tabular}{lccccc}
\hline & Full & Q1 & Q2 & Q3 & Q4 \\
\hline & $(1)$ & $(2)$ & $(3)$ & $(4)$ & $(5)$ \\
\hline$\gamma$ (Gradient) & $-0.247^{* * *}$ & $-0.258^{* * *}$ & $-0.265^{* * *}$ & $-0.248^{* * *}$ & $-0.215^{* * *}$ \\
& $(0.01)$ & $(0.01)$ & $(0.01)$ & $(0.01)$ & $(0.01)$ \\
Constant & $5.188^{* * *}$ & $5.128^{* * *}$ & $5.234^{* * *}$ & $5.267^{* * *}$ & $5.276^{* * *}$ \\
& $(0.03)$ & $(0.03)$ & $(0.03)$ & $(0.04)$ & $(0.05)$ \\
\hline $\mathrm{R}^{2}$ & 0.428 & 0.444 & 0.460 & 0.441 & 0.376 \\
Obs & 518530 & 130008 & 128254 & 130201 & 130067 \\
\hline
\end{tabular}

$* p<0.1,{ }^{* *} p<0.05,{ }^{* * *} p<0.01$. Sample restricted to Low Fares. All regressions include route, day-of-week, month and year FEs. Standard errors, clustered by route, in parentheses. 
Table 13: Regression of Fares on Advance Purchase Days: Domestic and Transborder Routes

\begin{tabular}{|c|c|c|}
\hline & Domestic & Transborder \\
\hline & (1) & $(2)$ \\
\hline High: 0 to 1 days & $\begin{array}{c}1.212^{* * *} \\
(0.04)\end{array}$ & $\begin{array}{c}1.728^{* * *} \\
(0.08)\end{array}$ \\
\hline High: 2 to 4 days & $\begin{array}{c}1.153^{* * *} \\
(0.05)\end{array}$ & $\begin{array}{c}1.589^{* * *} \\
(0.09)\end{array}$ \\
\hline High: 5 to 7 days & $\begin{array}{c}1.074^{* * *} \\
(0.05)\end{array}$ & $\begin{array}{c}1.454^{* * *} \\
(0.10)\end{array}$ \\
\hline High: 8 to 14 days & $\begin{array}{c}1.028^{* * *} \\
(0.05)\end{array}$ & $\begin{array}{c}1.124^{* * *} \\
(0.05)\end{array}$ \\
\hline High: 15 to 21 days & $\begin{array}{c}0.977^{* * *} \\
(0.05)\end{array}$ & $\begin{array}{c}0.684^{* * *} \\
(0.05)\end{array}$ \\
\hline High: 22 to 30 days & $\begin{array}{c}0.976^{* * *} \\
(0.06)\end{array}$ & $\begin{array}{c}0.555^{* * *} \\
(0.06)\end{array}$ \\
\hline High: 31 to 60 days & $\begin{array}{c}0.916^{* * *} \\
(0.06)\end{array}$ & $\begin{array}{c}0.436^{* * *} \\
(0.04)\end{array}$ \\
\hline High: $60+$ days & $\begin{array}{c}0.876^{* * *} \\
(0.07)\end{array}$ & $\begin{array}{c}0.304^{* * *} \\
(0.02)\end{array}$ \\
\hline Low: 0 to 1 days & $\begin{array}{c}0.804^{* * *} \\
(0.03)\end{array}$ & $\begin{array}{c}0.749^{* * *} \\
(0.05)\end{array}$ \\
\hline Low: 2 to 4 days & $\begin{array}{c}0.749^{* * *} \\
(0.03)\end{array}$ & $\begin{array}{c}0.686^{* * *} \\
(0.05)\end{array}$ \\
\hline Low: 5 to 7 days & $\begin{array}{c}0.617^{* * *} \\
(0.04)\end{array}$ & $\begin{array}{c}0.683^{* * *} \\
(0.03)\end{array}$ \\
\hline Low: 8 to 14 days & $\begin{array}{c}0.419^{* * *} \\
(0.04)\end{array}$ & $\begin{array}{c}0.452^{* * *} \\
(0.01)\end{array}$ \\
\hline Low: 15 to 21 days & $\begin{array}{c}0.173^{* * *} \\
(0.03)\end{array}$ & $\begin{array}{c}0.182^{* * *} \\
(0.01)\end{array}$ \\
\hline Low: 22 to 30 days & $\begin{array}{c}0.069^{* * *} \\
(0.02)\end{array}$ & $\begin{array}{c}0.091^{* * *} \\
(0.01)\end{array}$ \\
\hline Low: 31 to 60 days & $\begin{array}{c}0.022^{*} \\
(0.01)\end{array}$ & $\begin{array}{c}0.039^{* * *} \\
(0.01)\end{array}$ \\
\hline Constant & $\begin{array}{c}4.246^{* * *} \\
(0.06)\end{array}$ & $\begin{array}{c}4.284^{* * *} \\
(0.06)\end{array}$ \\
\hline $\mathrm{R}^{2}$ & 0.554 & 0.636 \\
\hline Obs & 508931 & 229573 \\
\hline \multicolumn{3}{|c|}{$\begin{array}{l}* p<0.1,{ }^{* *} p<0.05,{ }^{* * *} p<0.01 \text {. All re- } \\
\text { gressions include route, day-of-week, month and } \\
\text { year FEs. Standard errors, clustered by route, in } \\
\text { parentheses. }\end{array}$} \\
\hline
\end{tabular}


Table 14: Daysout Elasticities

\begin{tabular}{lccccc}
\hline $\begin{array}{l}\text { Route (to and } \\
\text { from Toronto) }\end{array}$ & \multicolumn{2}{c}{ Low Fares } & & \multicolumn{2}{c}{ High Fares } \\
\cline { 2 - 3 } \cline { 6 - 6 } & $\gamma$ & $N$ & & $N$ \\
\hline Montreal & -0.251 & 122634 & & -0.054 & 20359 \\
Ottawa & -0.270 & 130315 & -0.076 & 20334 \\
Thunder Bay & -0.193 & 36192 & & -0.083 & 2648 \\
\hline New York & -0.235 & 91906 & & -0.250 & 25722 \\
Boston & -0.254 & 31067 & & -0.489 & 11717 \\
Chicago & -0.169 & 26630 & & -0.483 & 12281 \\
\hline All Domestic & -0.246 & 420246 & & -0.064 & 58656 \\
All Transborder & -0.226 & 158962 & -0.379 & 51093 \\
All Routes & -0.244 & 579208 & -0.217 & 109749 \\
\hline
\end{tabular}

Note: $\gamma$ is the estimated price elasticity with regard to days remaining until travel, for the corresponding route(s) and fare type. Estimating regressions include route, day-of-week, month and year FEs. Sample restricted to purchases made within 90 days of travel. 
Table 15: Regression of Fares on Advance Purchase Days: Capacity Measures

\begin{tabular}{|c|c|c|c|c|c|c|}
\hline & \multicolumn{3}{|c|}{ Low Fares } & \multicolumn{3}{|c|}{ High Fares } \\
\hline & $(1)$ & $(2)$ & $(3)$ & $(4)$ & $(5)$ & (6) \\
\hline 0 to 1 days & $\begin{array}{c}0.812^{* * *} \\
(0.02)\end{array}$ & $\begin{array}{c}0.813^{* * *} \\
(0.02)\end{array}$ & $\begin{array}{c}0.816^{* * *} \\
(0.02)\end{array}$ & $\begin{array}{c}0.919^{* * *} \\
(0.11)\end{array}$ & $\begin{array}{c}0.920^{* * *} \\
(0.11)\end{array}$ & $\begin{array}{c}0.924^{* * *} \\
(0.11)\end{array}$ \\
\hline 2 to 4 days & $\begin{array}{c}0.756^{* * *} \\
(0.03)\end{array}$ & $\begin{array}{c}0.757^{* * *} \\
(0.03)\end{array}$ & $\begin{array}{c}0.761^{* * * *} \\
(0.03)\end{array}$ & $\begin{array}{c}0.869^{* * *} \\
(0.11)\end{array}$ & $\begin{array}{c}0.871^{* * *} \\
(0.11)\end{array}$ & $\begin{array}{c}0.876^{* * *} \\
(0.11)\end{array}$ \\
\hline 5 to 7 days & $\begin{array}{c}0.639^{* * * *} \\
(0.03)\end{array}$ & $\begin{array}{c}0.640^{* * * *} \\
(0.03)\end{array}$ & $\begin{array}{c}0.643^{* * * *} \\
(0.02)\end{array}$ & $\begin{array}{c}0.778^{* * * *} \\
(0.11)\end{array}$ & $\begin{array}{c}0.780^{* * * *} \\
(0.11)\end{array}$ & $\begin{array}{c}0.785^{* * * *} \\
(0.11)\end{array}$ \\
\hline 8 to 14 days & $\begin{array}{c}0.433^{* * * *} \\
(0.03)\end{array}$ & $\begin{array}{c}0.435^{* * * *} \\
(0.03)\end{array}$ & $\begin{array}{c}0.438^{* * * *} \\
(0.02)\end{array}$ & $\begin{array}{c}0.618^{* * * *} \\
(0.07)\end{array}$ & $\begin{array}{c}0.619 \text { *** } \\
(0.07)\end{array}$ & $\begin{array}{c}0.623^{* * *} \\
(0.07)\end{array}$ \\
\hline 15 to 21 days & $\begin{array}{c}0.180^{* * * *} \\
(0.02)\end{array}$ & $\begin{array}{c}0.181^{* * * *} \\
(0.02)\end{array}$ & $\begin{array}{c}0.185^{* * *} \\
(0.02)\end{array}$ & $\begin{array}{c}0.381^{* * * *} \\
(0.02)\end{array}$ & $\begin{array}{c}0.382^{* * * *} \\
(0.02)\end{array}$ & $\begin{array}{c}0.385^{* * *} \\
(0.02)\end{array}$ \\
\hline 22 to 30 days & $\begin{array}{c}0.080^{* * * *} \\
(0.01)\end{array}$ & $\begin{array}{c}0.081^{* * * *} \\
(0.01)\end{array}$ & $\begin{array}{c}0.084^{* * * *} \\
(0.01)\end{array}$ & $\begin{array}{c}0.278^{* * * *} \\
(0.02)\end{array}$ & $\begin{array}{c}0.279^{* * * *} \\
(0.02)\end{array}$ & $\begin{array}{c}0.283^{* * * *} \\
(0.02)\end{array}$ \\
\hline 31 to 60 days & $\begin{array}{c}0.030^{* * * *} \\
(0.01)\end{array}$ & $\begin{array}{c}0.031^{* * *} \\
(0.01)\end{array}$ & $\begin{array}{c}0.033^{* * * *} \\
(0.01)\end{array}$ & $\begin{array}{c}0.141^{* * * *} \\
(0.02)\end{array}$ & $\begin{array}{c}0.142^{* * *} \\
(0.02)\end{array}$ & $\begin{array}{c}0.143^{* * *} \\
(0.02)\end{array}$ \\
\hline Remaining Seats (\%) & & $\begin{array}{c}-0.066^{* * *} \\
(0.01)\end{array}$ & & & $\begin{array}{c}-0.074^{* * *} \\
(0.02)\end{array}$ & \\
\hline Load Factor (\%) & & & $\begin{array}{c}0.145^{* * *} \\
(0.02)\end{array}$ & & & $\begin{array}{c}0.176^{* * *} \\
(0.03)\end{array}$ \\
\hline Constant & $\begin{array}{c}4.237^{* * * *} \\
(0.04)\end{array}$ & $\begin{array}{c}4.285^{* * *} \\
(0.05)\end{array}$ & $\begin{array}{c}4.163^{* * *} \\
(0.04)\end{array}$ & $\begin{array}{c}4.743^{* * *} \\
(0.12)\end{array}$ & $\begin{array}{c}4.795^{* * * *} \\
(0.12)\end{array}$ & $\begin{array}{c}4.646^{* * * *} \\
(0.11)\end{array}$ \\
\hline $\mathrm{R}^{2}$ & 0.434 & 0.435 & 0.437 & 0.348 & 0.349 & 0.351 \\
\hline $\mathrm{R}^{2}$ excl. Daysout & 0.153 & 0.153 & 0.155 & 0.160 & 0.161 & 0.162 \\
\hline Obs & 589704 & 589704 & 589704 & 108207 & 108207 & 108207 \\
\hline
\end{tabular}

$* p<0.1,{ }^{* *} p<0.05, * * * p<0.01$. All regressions include route, day-of-week, month and year FEs. Standard errors, clustered by route, in parentheses. High Fares include only Adjustable tickets in Column 1, and also include Refundable tickets in Column 2. 